\title{
Intensified Carbon Capture using Adsorption: Heat Transfer Challenges and Potential Solutions
}

\author{
Jonathan R. McDONOUGH, Richard LAW, David A. REAY*, Vladimir ZIVKOVIC \\ *Corresponding author: Tel.: +44 (0)191 208 5604; Email: david.reay@ @ewcastle.ac.uk \\ School of Engineering, Newcastle University, Newcastle upon Tyne NE1 7RU, UK
}

\begin{abstract}
Up to $25 \%$ of the total European Union (EU) $\mathrm{CO}_{2}$ emissions that contribute to global warming are from industry, and while improved energy efficiency and process integration continues to play a role in minimizing these, it is carbon capture (CC) that in future will contribute most to mitigation, until nuclear energy and renewable technologies take over from fossil fuels. One of several CC methods is to use gas-solid adsorption, where the $\mathrm{CO}_{2}$ is adsorbed onto a solid. As with the more common absorption process, regeneration is required, and typically a single bed is employed to adsorb $\mathrm{CO}_{2}$ while regeneration and removal of the $\mathrm{CO}_{2}$ takes place in the second bed - carried out by pressure swing adsorption (PSA) or temperature swing adsorption (TSA). Collaborating in an EPSRC-funded project with Heriot-Watt University, where hydrotalcite-based adsorbents are being synthesised, and Sheffield University, where modelling is being undertaken, Newcastle University is examining the intensification of CC using a TSAbased process involving swirling or toroidal fluidized beds. As well as improving adsorption, it is believed that recovered waste heat could be used for desorption using a similar intensified technology. This paper discusses the potential sources of $\mathrm{CO}_{2}$ that are being addressed, and how they will be integrated with the capture and desorption processes where fluidization will be used for the adsorption process. It also describes preliminary work on fluidization of the particles using additive-manufactured miniaturized fluid beds.
\end{abstract}

Keywords: Heat transfer, Carbon Capture, Adsorption, Fluidization, Additive Manufacture

\section{Nomenclature}

$\mathrm{d}_{\mathrm{p}} \quad$ Average diameter of adsorbent particle $(\mathrm{m})$

$\mathrm{h}_{\max } \quad$ Maximum heat transfer coefficient $\left(\mathrm{W} \cdot \mathrm{m}^{-2} \cdot \mathrm{K}^{-1}\right)$

$\mathrm{k}_{\mathrm{g}} \quad$ Thermal conductivity of fluidizing gas $\left(\mathrm{W} \cdot \mathrm{m}^{-1} \cdot \mathrm{K}^{-1}\right)$

\section{Greek Letters}

$\rho_{\mathrm{p}} \quad$ Adsorbent particle density (kg. $\left.\mathrm{m}^{-3}\right)$

$\rho_{\mathrm{sb}} \quad$ Bulk density of the adsorbent particle bed $\left(\mathrm{kg} \cdot \mathrm{m}^{-3}\right)$

$\begin{array}{ll}\text { Abbreviations } & \\ \text { CC } & \text { Carbon Capture } \\ \text { EPSRC } & \text { Engineering and Physical Sciences Research Council } \\ \text { EU } & \text { European Union } \\ \text { IPCC } & \text { Intergovernmental Panel on Climate Change } \\ \text { MEA } & \text { Monoethanolamine } \\ \text { PSA } & \text { Pressure Swing Adsorption } \\ \text { TSA } & \text { Temperature Swing Adsorption }\end{array}$




\section{Introduction}

Industrial processes have historically been prolific emitters of atmospheric pollutants, and while the situation has improved significantly since the middle of the last Century, through environmental legislation and the need for energy efficiency to reduce costs, the growing awareness of $\mathrm{CO}_{2}$ emissions and their impact on global warming has led to industrial plants considering carbon capture. Most carbon capture discussion has centred on power generation using fossil fuels, but with industrial process $\mathrm{CO}_{2}$ emissions in the European Union accounting for $25 \%$ of the total, action is needed to address this problem. The EU has committed to three targets for 2020 . The first is to reduce emissions by $20 \%$ on 1990 levels. The second is to provide $20 \%$ of its total energy from renewables. The third is to increase energy efficiency by $20 \%$ from 2007 levels. EU leaders have also endorsed an $80-95 \%$ reduction in emissions by 2050 [1].

It has been estimated that $25 \%$ of the total $\mathrm{EU} \mathrm{CO}_{2}$ emissions are from industry, and while improved energy efficiency and process integration continues to play a role in minimizing these, it is carbon capture (CC) that in future will play the major role in mitigation, unless/until nuclear energy and/or a range of renewable technologies take over from fossil fuels. As in power stations, CC is likely to become a necessary addition to existing industrial processes that are deemed to be significant emitters of $\mathrm{CO}_{2}$. An important question that industry is trying to address is the correct choice of CC technology to adopt.

Probably the greatest amount of effort to date, certainly in the case of power plant emissions control, has been expended on liquid absorption-based systems, the most common absorbent being MEA (monoethanolamine). Amines degrade over time and can react with impurities in the gas stream to produce toxic substances that might be lost to the atmosphere. Work at CSIRO in Australia [2] is attempting to quantify the loss of MEA due to oxidative degradation, and each of these mechanisms increase the need to replenish MEA in the systems - a costly process.

Attempts to reduce the physical impact and cost of absorption systems for CC have concentrated upon intensifying the ab- and desorption processes using high gravity fields in a rotating packed bed [3]. An alternative $\mathrm{CC}$ method is to use gas-solid adsorption, where the $\mathrm{CO}_{2}$ is adsorbed onto a solid. The solid is normally in the form of particles of adsorbent, on a fixed bed. As with absorption, regeneration is required, and typically a single bed is employed to adsorb $\mathrm{CO}_{2}$ while regeneration and removal of the $\mathrm{CO}_{2}$ takes place in the second bed - carried out by pressure swing adsorption (PSA) [4] or temperature swing adsorption (TSA).

Collaborating in an EPSRC-funded project [5] with Heriot-Watt University, where hydrotalcite-based adsorbents are being synthesised, and Sheffield University, where modelling is being undertaken, Newcastle University is examining the intensification of CC using a TSA-based process involving swirling [6] or toroidal [7] fluidized beds. The raison d'être is based upon two observations: firstly, current state-of-the-art for reducing the energy demand for solvent regeneration has developed solid adsorbents (working capacity $>3 \mathrm{mmol} / \mathrm{g}$ ), where the required energy for adsorption can be 30-50\% lower than that reported for absorption using MEA [8]. Secondly, and in contrast to CC for power generation, significant gains can be made in the area of energy efficiency and sorbent regeneration by recovering waste heat in industrial processes. Newcastle University has identified the primary $\mathrm{CO}_{2}$ sources in three key industrial sectors (Cement, Iron \& Steel and Refineries) where there also exists substantial waste heat streams that potentially could be used for sorbent regeneration.

Heat transfer in static beds of adsorbent is largely ineffective and both ad- and desorption can be timeconsuming. In order to enhance heat (and mass) transfer, we are measuring the performance of adsorbents in, initially, micro-fluidized beds that are made by additive manufacturing on site, starting with a circulating fluidized bed, then moving on to a Swirling Fluidized Bed or Toroidal Fluidized Bed-type unit (see Section 3 , where a Torbed unit, a commercially available variant, is shown), culminating in a pilot plant. As well as adsorbing, we are examining configurations that will connect the first bed to a desorber that will be linked to the adsorber bed to effect a continuous regeneration process (as done in absorption). This may mirror the 'racetrack' $[9,48]$ that was proposed for heat recovery - a role that may aid the regeneration of the adsorbent particles. 
In this paper we discuss the industrial heat sources that may be treated by adsorption to effectively remove $\mathrm{CO}_{2}$, before describing the adsorption/desorption technologies that are being studied. Data are given on the experimental programme and the use of additive manufacturing to produce prototype fluidized bed configurations that can be readily applied as adsorbers.

\section{Industrial Sources of $\mathrm{CO}_{2}$}

As briefly discussed in the Introduction, industrial processes account for a large proportion (typically 25\%) of $\mathrm{CO}_{2}$ emissions in the European Union. It is also rather important to address these sources, as well as those from power generation plants, because unlike the increasing trend seen with the latter, renewables are unlikely to replace fossil fuels in major industries in the foreseeable future. Of the industrial processes, the most important ones to address are cement production, iron and steel production, oil refining, natural gas processing, and metals production [10,11]. Data from the IPCC report on the major emitters (excluding natural gas processing) are shown in the diagram in Figure 1.

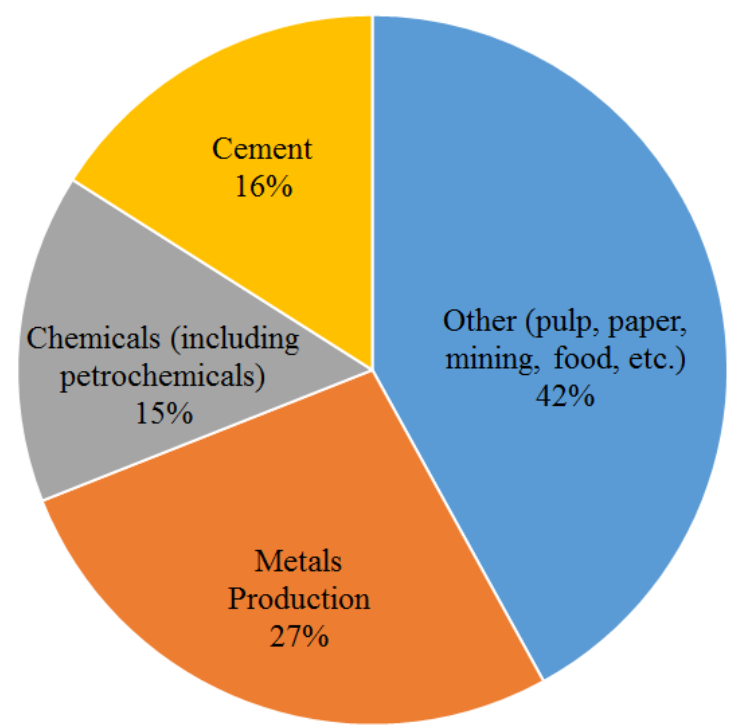

Figure 1. Global industrial sources of $\mathrm{CO}_{2}$ in 2010. Excluding indirect emissions (e.g. electricity generation) [1]

In order to find suitable $\mathrm{CO}_{2}$ sources and to identify the availability of waste heat for adsorbent regeneration, the cement, chemicals and metals production (specifically iron and steel) were studied as to their suitability. In all cases a primary source of $\mathrm{CO}_{2}$ was identified which could (or should) be targeted for capture in this project. However, only in the cement and iron/steel industries does there appear to be an opportunity for waste-heat integrated regeneration of capture sorbents by TSA, as comprehensive waste-heat integration is already employed in the refineries sector. Therefore, the target sectors were defined as iron \& steel and cement, and no further analysis was carried out for the refineries sector. (It should be noted that the temperature of waste heat was critical - the data based upon the analysis of the authors in this respect, that led to the rejection of oil refining were verified by data in [12], the comprehensive study by Element Energy, who extensively studied the potential for waste heat recovery in oil refineries and found the maximum heat source temperature to be $150^{\circ} \mathrm{C}$ ).

The two target carbon sources have similarities in composition, summarised as follows:

- $\mathrm{CO}_{2}$ concentration in the range 20-28mol\%. Hence, any sorbents synthesised in the project should be tested for $\mathrm{CO}_{2}$ uptake in streams of this concentration.

- Absolute humidity in the range of 7-11mol\%. Hence, any sorbents synthesised in the project should be designed to be able to withstand this degree of humidity (and tested to prove such credentials). Further, it will be important to test the effect of this humidity on fluidization of the particles, [13]. If 
this humidity is found to be a problem for either of the reasons noted, then a dehumidification step will have to be included in the overall process design.

- CO concentration of $0 \%$. Hence, this is not a concern.

- Significant $S O_{x}$ and $N O_{x}$ concentrations. Hence, the sorbents synthesised in this project should be designed to be able to withstand the presence of $\mathrm{SO}_{\mathrm{x}}$ and $\mathrm{NO}_{\mathrm{x}}$ (and tested to prove such credentials). If this is found to be problematic, then a scrubbing step must be included in the overall process design. Schneider [14] investigated carbon capture in the cement industry using an amine absorption process and found that the capital cost of scrubbers to pre-clean the stack gas would be $\sim 7 \%$ of the total capital of the project. Hence, the cost is likely to be insignificant compared to that of the $\mathrm{CO}_{2}$ capture and compression process. It is assumed that the economics would be similar for the steel industry power plant stack gas.

- Both sources are at atmospheric pressure. This suggests that TSA may be the preferred regeneration strategy.

One significant difference between the two $\mathrm{CO}_{2}$ sources is the temperature; $80-180^{\circ} \mathrm{C}$ in the cement industry stack gas, and $300^{\circ} \mathrm{C}$ in the iron/steel power plant stack (see Table 1). Here, it is proposed that the target temperature is set to a maximum of $180^{\circ} \mathrm{C}$ based on the following rationale:

- It is considered easier to design for one temperature carbon source than for multiple sources.

- A pre-cooling step in the iron/steel industry case would be easy to design and include; this excess heat could also be used for pre-heating the regeneration process prior to TSA through heat integration.

- This range should still allow chemisorption of $\mathrm{CO}_{2}$ onto the sorbents; it being believed that $\mathrm{CO}_{2}$ uptake would be significantly higher under chemisorption than physisorption, and that the temperature at which chemisorption is initiated is in the range $20-200^{\circ} \mathrm{C}$.

Table 1. Summary of the $\mathrm{CO}_{2}$ source data for the two selected industrial sectors

\begin{tabular}{|c|c|c|}
\hline Sector & Cement & Iron \& Steel \\
\hline $\mathrm{CO}_{2}$ Source & Stack Gas & Power Plant Stack \\
\hline Pressure (kPa) & 101.3 & 101.3 \\
\hline Temperature $\left({ }^{\circ} \mathrm{C}\right)$ & $80-180$ & 300 \\
\hline \multicolumn{3}{|l|}{ Composition } \\
\hline $\mathrm{CO}_{2}(\mathrm{~mol} \%)$ & $19-22$ & $23-28$ \\
\hline $\mathrm{N}_{2}+\operatorname{Air}(\mathrm{mol} \%)$ & $67-68$ & 68 \\
\hline $\mathrm{O}_{2}(\mathrm{~mol} \%)$ & $2-4$ & 1 \\
\hline $\mathrm{H}_{2} \mathrm{O}(\mathrm{mol} \%)$ & $7-11$ & 8 \\
\hline $\mathrm{CO}(\mathrm{mol} \%)$ & 0 & 0 \\
\hline $\mathrm{SO}_{\mathrm{x}}(\mathrm{ppm})$ & 60 & $>200$ \\
\hline $\mathrm{NO}_{\mathrm{x}}(\mathrm{ppm})$ & $200-3000$ & $>200$ \\
\hline
\end{tabular}

The flow rate of the "Power Plant Stack" gas from the Iron/Steel industry is known to be $400 \mathrm{~m}^{3} / \mathrm{s}$ for a typical plant that produces 5 million tonnes of steel per year [15]. The flow rate of the cement industry "Stack gas" is not known, though it can be inferred as follows. The carbon generated per tonne of clinker is $800 \mathrm{~kg} /$ tonne of clinker. This is excluding indirect emissions (i.e. this is the amount emitted from the stack gas itself). Conversion of mol\% to mass\% (assuming mass of $\mathrm{CO}_{2}, \mathrm{NO}_{\mathrm{x}}$ and $\mathrm{SO}_{\mathrm{x}}$ are negligible) is achieved in Table 2:

Table 2. Conversion of moles per 1 mole stack gas (mol\%) to mass \%

\begin{tabular}{l|llll|l} 
& $\mathrm{CO}_{2}$ & $\mathrm{~N}_{2}$ & $\mathrm{O}_{2}$ & $\mathrm{H}_{2} \mathrm{O}$ & TOTAL \\
\hline Moles per 1 mole gas (mol) & 0.22 & 0.67 & 0.02 & 0.09 & 1 \\
Molar mass (g/mol) & 44 & 28 & 32 & 18 & - \\
Grams per 1 mole gas (g) & 0.005 & 0.024 & 0.00063 & 0.005 & 0.035 \\
mass\% & 14.4 & 69.3 & 1.8 & 14.4 & -
\end{tabular}


The $800 \mathrm{~kg}$ of carbon per tonne of clinker corresponds to 14.4 mass $\%$ of the total flow rate; thus, the total flow rate of the stack gas can be calculated as $5556 \mathrm{~kg} /$ tonne (clinker). This corresponds to a volumetric flow rate of $4790 \mathrm{~m}^{3} /$ tonne (clinker). In the UK, recent (2014) data suggest that typical cement production is 10 million tonnes per annum, spread across 13 sites [16]. Hence, the average UK cement works produces 770,000 tonnes of cement per annum. Based upon these production data and an assumption of 8000 operational hours per year, one can estimate typical cement production rates at a UK cement plant to be 97 tonne $/ \mathrm{h}$, or $27 \mathrm{~kg} / \mathrm{s}$. This corresponds to a stack gas mass flow rate of $150 \mathrm{~kg} / \mathrm{s}$, and stack gas volumetric flow rate of $129 \mathrm{~m}^{3} / \mathrm{s}$. The mass flow of $\mathrm{CO}_{2}$ in the stack gas is $21.6 \mathrm{~kg} / \mathrm{s}$. The flow rate of $\mathrm{CO}_{2}$ in the iron and steel industry power plant stack is calculated using a similar methodology; the total flow rate of $400 \mathrm{~m}^{3} / \mathrm{s}$ gives a mass flow of $\mathrm{CO}_{2}$ of $71 \mathrm{~kg} / \mathrm{s}$. A summary of the data for the "primary" heat sources identified in each industry is shown in Table 3 below.

Table 3. Summary of primary heat source data for each sector

\begin{tabular}{|c|c|c|}
\hline Sector & Cement & Iron \& Steel \\
\hline Stream & Cooler Exhaust & Basic Oxygen Furnace Off-Gas \\
\hline Phase & Gas & Gas \\
\hline Flow Rate ${ }^{+}(\mathrm{kg} / \mathrm{kg}$ solid $)$ & 1.42 & 0.30 \\
\hline Specific Heat Capacity ${ }^{2}(\mathrm{~kJ} / \mathrm{kg} . \mathrm{K})$ & 1.0 & 1.0 \\
\hline Temperature $\left({ }^{\circ} \mathrm{C}\right)$ & 400 & 1700 \\
\hline Enthalpy (kJ/kg solid) & 568 & 508 \\
\hline
\end{tabular}

The heat load of each source is calculated by multiplying the enthalpy $(\mathrm{kJ} / \mathrm{kg})$ by the production rate $(\mathrm{kg} / \mathrm{s})$. For the cement industry, the average production rate of cement is estimated as $27 \mathrm{~kg} / \mathrm{s}$. For the steel industry, the carbon source data is based on a typical UK integrated process site with an annual production of $5,000,000$ tonne/year. Assuming continuous operation and 8000 hours per year of plant time, the average production rate is $174 \mathrm{~kg} / \mathrm{s}$ of steel. Therefore, the waste heat loads in the cement industry "cooler exhaust" and iron and steel industry "basic oxygen furnace (BOF) off-gas" are calculated to be $15.3 \mathrm{MW}$ and 88.4 MW respectively.

A simplified dataset for the two selected sectors is summarised in Table 4. This allows one to state the problem as: "to capture $w \mathrm{~kg} / \mathrm{s}$ of carbon in a stream at $x{ }^{\circ} \mathrm{C}$ and regenerate using y $M W$ of waste heat at $z$ ${ }^{\circ} \mathrm{C}$ ". However, stream impurities (previously discussed) and concentrations must also be considered during sorbent design and synthesis. Both streams for capture and regeneration contain impurities in the form of gases and particulates that must be taken into account in the system design.

Table 4. Dataset for the Cement and Iron and Steel Sector $\mathrm{CO}_{2}$ Capture

\begin{tabular}{lll}
\hline & Cement & Iron \& Steel \\
\hline $\mathrm{CO}_{2}$ Source Name & Stack Gas & Power Plant Stack \\
$\mathrm{CO}_{2}$ Source Temperature $\left({ }^{\circ} \mathrm{C}\right)$ & 180 & 300 \\
$\mathrm{CO}_{2}$ Source Total Volumetric Flow Rate $\left(\mathrm{m}^{3} / \mathrm{s}\right)$ & 129 & 400 \\
$\mathrm{CO}_{2}$ Source Total Mass Flow Rate $(\mathrm{kg} / \mathrm{s})$ & 150 & 464 \\
$\mathrm{CO}_{2}$ Component Mass Flow Rate $(\mathrm{kg} / \mathrm{s})$ & 21.6 & 71 \\
\hline Heat Source & Cooler Exhaust & BOF off-gas \\
Heat Source Temperature $\left({ }^{\circ} \mathrm{C}\right)$ & 400 & 1700 \\
Heat Source Load $(\mathrm{MW})$ & 15.3 & 88.4 \\
Heat available per kg $\mathrm{CO}_{2}(\mathrm{MJ} / \mathrm{kg})$ & 0.71 & 1.25 \\
Max. Temperature Swing $\left({ }^{\circ} \mathrm{C}\right)$ & 220 & 1520 \\
(Assuming adsorption temperature of $\left.180^{\circ} \mathrm{C}\right)$ & & \\
\hline
\end{tabular}

\section{Tailoring Hydrotalcites for Industry, and Hydrotalcite Quantity}

Hydrotalcites are basic clay-like materials that exhibit modest $\mathrm{CO}_{2}$ capacities; typically around $1 \mathrm{mmol} / \mathrm{g}$ at temperatures of $200-500{ }^{\circ} \mathrm{C}$. Nonetheless, hydrotalcites have been identified as a suitable candidate for carbon capture from hot and wet effluent streams because they are thermally stable, relatively cheap to produce, exhibit fast sorption kinetics and possess high $\mathrm{CO}_{2}$ selectivities, even in the presence of water. Hydrotalcites are layered doubled hydroxides (LDHs) comprising alternative positively charged layers of 
metal oxides and interlayers containing water and anions. The general structure of $\mathrm{LDHs}$ is $\left[\mathrm{M}^{2+}{ }_{1-}\right.$ $\left.{ }_{x} \mathrm{M}^{3+}{ }_{\mathrm{x}}(\mathrm{OH})_{2}\right]^{\mathrm{x}+}\left[\mathrm{A}^{\mathrm{n}-}{ }_{\mathrm{x} / \mathrm{n} .} \cdot \mathrm{yH}_{2} \mathrm{O}\right]$, where $\mathrm{M}^{2+}$ and $\mathrm{M}^{3+}$ are the divalent (e.g. $\mathrm{Mg}^{2+}, \mathrm{Ni}^{2+}, \mathrm{Zn}^{2+}$, etc.) and trivalent (e.g. $\mathrm{Al}^{3+}, \mathrm{Ga}^{3+}, \mathrm{Mn}^{3+}, \mathrm{Y}^{3+}, \mathrm{Fe}^{3+}$, etc.) metal cations contained within brucite-like sheets and $\mathrm{A}^{\mathrm{n}-}$ is a charge compensating anion (e.g. $\mathrm{CO}_{3}{ }^{2-}, \mathrm{Cl}^{-}, \mathrm{SO}_{4}{ }^{2-}$, etc.) located in the interlayer space (Figure 2). Hydrotalcites typically contain $\mathrm{Mg}^{2+}, \mathrm{Al}^{3+}$ and $\mathrm{CO}_{3}{ }^{2-}$, with an $\mathrm{Mg} / \mathrm{Al}$ ratio of $\sim 3$ as the de-facto standard [17].

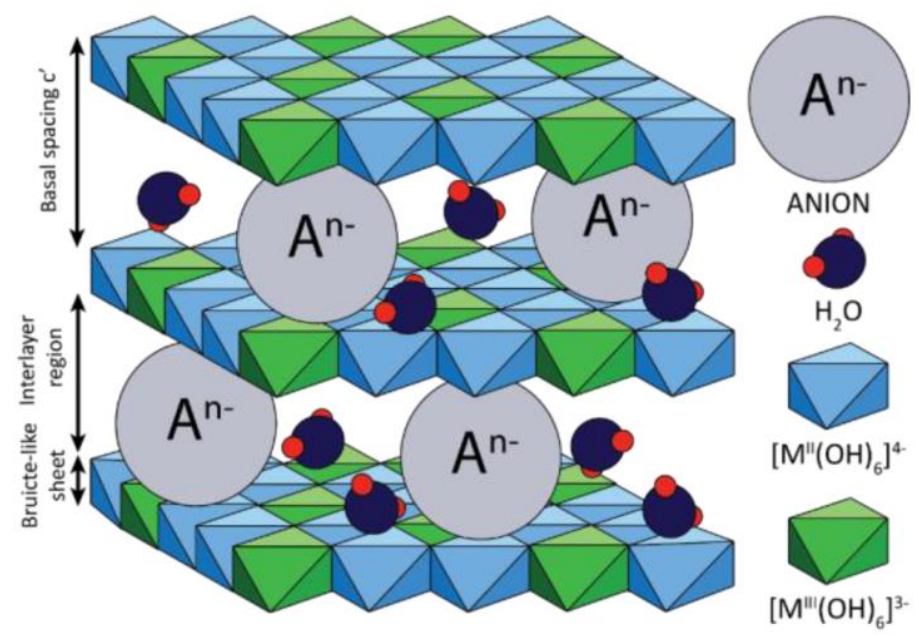

Figure 2. Basic structure of hydrotalcites [18]

Hydrotalcites adsorb $\mathrm{CO}_{2}$ through physisorption and chemisorption. Importantly, their performance can be tailored towards the target industrial $\mathrm{CO}_{2}$ source conditions using a number of methods. For instance, $\mathrm{CO}_{2}$ uptake capacities as high as $9.27 \mathrm{mmol} / \mathrm{g}$ were reported by adjusting the ratio of $\mathrm{Mg} / \mathrm{Al}$ from 3 to 30 [19]. For comparison, the capacity of the more established MEA absorbent is around $0.174 \mathrm{~mol} \mathrm{CO} / 2 \mathrm{~mol} \mathrm{MEA}$ after $30 \mathrm{~min}$ of contact [20], equivalent to $2.85 \mathrm{mmol} / \mathrm{g}$. Increased surface basicity is also known to promote higher affinity and selective binding of the acidic $\mathrm{CO}_{2}$. The basicity can be tuned using the calcination temperature, or by impregnating with elements that increase basicity such as $\mathrm{K}_{2} \mathrm{CO}_{3}$ [21]. Larger anions with higher charges also increase the $\mathrm{CO}_{2}$ capacity by increasing the interlayer spacing/void space; $\mathrm{CO}_{3}{ }^{2-}$ has been found to produce high $\mathrm{CO}_{2}$ capacities, whilst the addition of $\mathrm{NaNO}_{3}$ to the interlayer also positively influences the $\mathrm{CO}_{2}$ capacity [21]. Other modifications such as doping with rare earth elements [22], impregnating with alkali metals (such as $\mathrm{K}^{+}, \mathrm{Cs}^{+}, \mathrm{Na}^{+}$, etc.) [23] and changing the cations/anions [24,25] are described. Finally, the synthesis conditions, such as $\mathrm{pH}$ [25] and aging process (e.g. conventional heating, microwave heating, etc. [26,27], have been used to modify uptake behaviour.

As a preliminary estimate, using the $9.27 \mathrm{mmol} / \mathrm{g}$ capacity quoted in the literature [19], 53.0 and $174.1 \mathrm{~kg} / \mathrm{s}$ of hydrotalcite would be needed to capture $100 \%$ of the $\mathrm{CO}_{2}$ from the cement and iron/steel industries respectively based on the data reported in Table 4. Assuming a 5 min cycle time, this corresponds to total loads of 15.9 tonnes and 52.2 tonnes of hydrotalcite sorbent. The distribution of solids between the capture and regeneration units will depend on the specific adsorption and desorption kinetics. The hydrotalcite quantity required for complete $\mathrm{CO}_{2}$ capture can be decreased by increasing the cyclic load capacity of the hydrotalcite, and/or improving the adsorption and desorption kinetics. This is currently being investigated by Heriot-Watt University using the methods described above, with the additional goal to optimise their synthesis and scale-up. The various synthesis routes currently being explored to optimise the hydrotalcutes to the conditions shown in Table 4 include: (a) co-hydration, (b) amide hydrolysis, (c) co-precipitation, (d) post-synthesis modification and (e) in-situ generation of clay-supported mixed metal oxides. At the present stage in the project it is not possible to evaluate the efficiency of the proposed $\mathrm{CO}_{2}$ capture technology. However, the efficiency will be evaluated in the final work package, which will also deliver the whole system integration, life cycle assessment, and techno-economic assessment. 


\section{Intensification of Adsorption using a Toroidal Fluidized Bed 4.1 Adsorption}

Adsorption using solid sorbents offers several advantages compared to liquid-based absorption. From an engineering perspective, advantages include eliminated liquid waste streams, simple disposal routes for benign solids waste and a wide range of compatible operating temperatures [10]. Additionally, solid adsorbents are not volatile, and can avoid the large energy penalties associated with the regeneration of liquid absorbents due to the requirement to evaporate water in the stripper [28]. From a materials perspective, solid sorbents possess higher cyclic $\mathrm{CO}_{2}$ capacities per unit weight than liquid absorbents and the chemistries of solid sorbents can be more easily tuned [29].

Adsorption technologies are broadly classified as fixed or moving. Fixed bed adsorption typically involves the use of packed beds containing either pelletized sorbents (in a random arrangement) or structured sorbents (created by using a binding agent or impregnating the sorbent in a substrate). These packed beds can be configured as single vessels, or used in simulated moving bed or rotating arrangements [30]. Moving adsorption systems are any system that involves the transport of powdered/pelletized sorbents between different vessels for adsorption/regeneration; examples include moving beds and fluidized beds. The advantages and challenges of fixed and moving adsorption are summarised in Table 5.

Table 5. Advantages and challenges of fixed and moving bed adsorption [10,29]

\begin{tabular}{|c|c|c|}
\hline & Fixed Bed & Moving Bed \\
\hline Advantages & $\begin{array}{l}\text { - Low sorbent degradation/attrition rates } \\
\text { - Controllable pressure drop (using } \\
\text { structured packings) }\end{array}$ & $\begin{array}{l}\text { - Continuous (steady-state) operation } \\
\text { - } \quad \text { Full utilisation of the particle bed } \\
\text { - Thermal mass of equipment can be } \\
\text { ignored } \\
\text { - Online sorbent replacement/treatment } \\
\text { - Simpler heat transfer }\end{array}$ \\
\hline Challenges & $\begin{array}{l}\text { - Non-steady state operation } \\
\text { - Only a small section of the bed is } \\
\text { actively involved in adsorption at any } \\
\text { one time (mass transfer zone) } \\
\text { - Heat transfer must be designed to avoid } \\
\text { sorbent overheating (via the release of } \\
\text { heat of adsorption) and avoid energy } \\
\text { penalties associated with the loss of } \\
\text { liberated heat } \\
\text { - Dead-space volumes }\end{array}$ & $\begin{array}{l}\text { - Enhanced sorbent attrition } \\
\text { - Non-uniform residence times } \\
\text { - } \quad \text { Operation and control }\end{array}$ \\
\hline
\end{tabular}

The total cost for implementing adsorptive $\mathrm{CO}_{2}$ capture is driven by both the system size and operating cost [29]. The size of the adsorber is defined according to the cycle time (defined as $\mathrm{CO}_{2}$ uptake per cycle per unit volume of material) and the desired $\mathrm{CO}_{2}$ capture duty. The cyclic capacity is mainly governed by the choice of sorbent material, but could also be influenced by the design of the adsorber itself. For instance, a fluidized bed might necessitate a larger particle diameter than a packed bed to avoid elutriation, which would introduce additional mass transfer resistances. MacDowell et al. [30] describe the main challenges for selecting solid sorbents for industrial adsorption via drop-off in cyclic capacity over time due to sintering, attrition and chemical deactivation. The operating cost is principally affected by the energy requirement of the regeneration process, but should also consider any energy penalties associated with modifications to the process that result from the addition of a carbon capture system (e.g. loss of delivered power from a power station). An intensified adsorber system must therefore not require extensive modification of the sorbent material (e.g. agglomeration to increase particle size) and should be easily retrofitted to the existing process without requiring substantial alteration.

Temperature swing adsorption (TSA) is of interest for this project because it is compatible with the direct utilisation of waste heat from the process of interest; suitable waste heat sources have been identified in both 
the cement and iron/steel processes (as summarised in Table 3). Although pressure swing adsorption (PSA) is usually preferred because it is much faster than TSA, vacuum swing adsorption (VSA) would be necessary to avoid the need to pressurise the flue gas prior to adsorption. This would require multi-stage vacuum units to achieve the low pressures needed for regeneration $(<5 \mathrm{kPa})$, increasing the cost/power requirements [28]. Another development is rapid temperature swing adsorption (RTSA). For example, Lively et al. [31] describe the use of hollow fibre adsorbents that contain an impermeable core that can incorporate cooling or heating agents for more efficient adsorption and rapid regeneration respectively. Although elevated attrition would be likely, a fluidized bed system would be theoretically smaller because of the lower inventory of material (all of the fluidized bed would be actively involved in adsorption).

\subsection{Toroidal Fluidized Bed Concept}

In this project, it is proposed that a toroidal fluidized bed (the commercially-available unit being called the Torbed) can deliver a new approach for realising intensified adsorption using TSA. The toroidal fluidized bed, also referred to as the swirling fluidized bed (SFB) or vortexing fluidized bed (VFB) in the literature, involves fluidising a particle bed using a swirling gas stream generated using either an angled blade distributor or tangential inlet gas stream. The two main configurations of the angled blade design available from Torftech, the manufacturer of the Torbed variant, are the Compact Bed Reactor (CBR) and Expanded Bed Reactor (EBR), whose schematics are shown in Figure 3.

The Torbed and other similar concepts use inclined blades to impart tangential motion to the fluidising gas. The vertical velocity component provides fluidization, while the horizontal velocity component produces swirling motion around the annulus. Entrainment of the particles is minimised because the majority of the gas stream momentum is dissipated at the base of the bed in the radial and tangential directions, while the central cone results in an increasing cross-sectional area moving away from the distributor. This allows smaller particle sizes to be "fluidisable" compared to conventional fluidized beds. These smaller particles present smaller thermal masses, allowing for more rapid heating and cooling, and decreased internal diffusion pathlengths leading to intensified mass transfer. Energy dissipation by the distributor also results in high amounts of turbulence in the bed, causing thinning of the boundary layers around the particles leading to further intensification of heat and mass transfer [32]. 
(a)
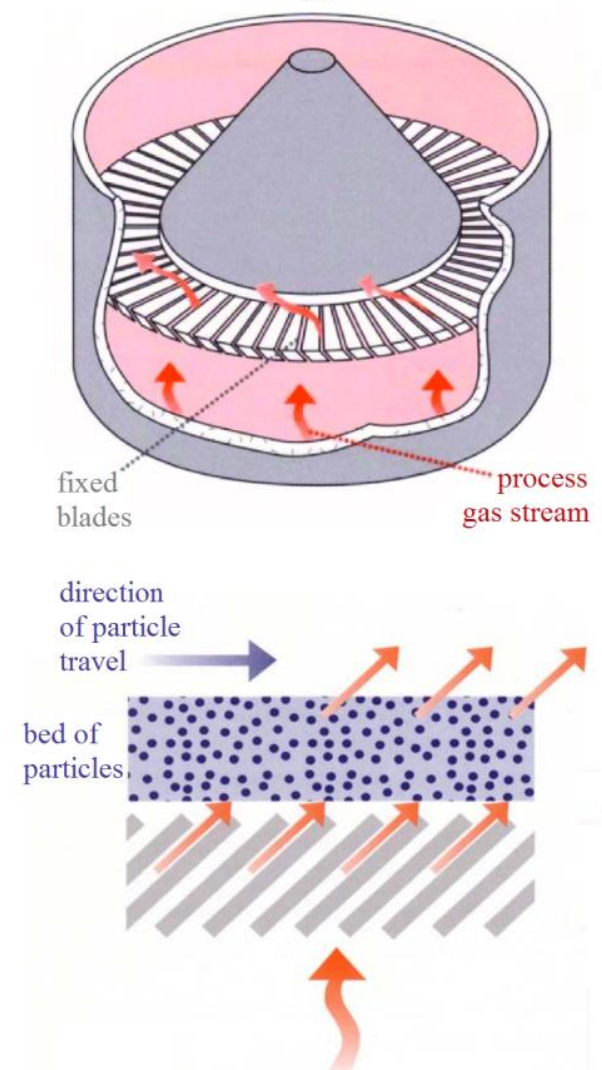

(b)

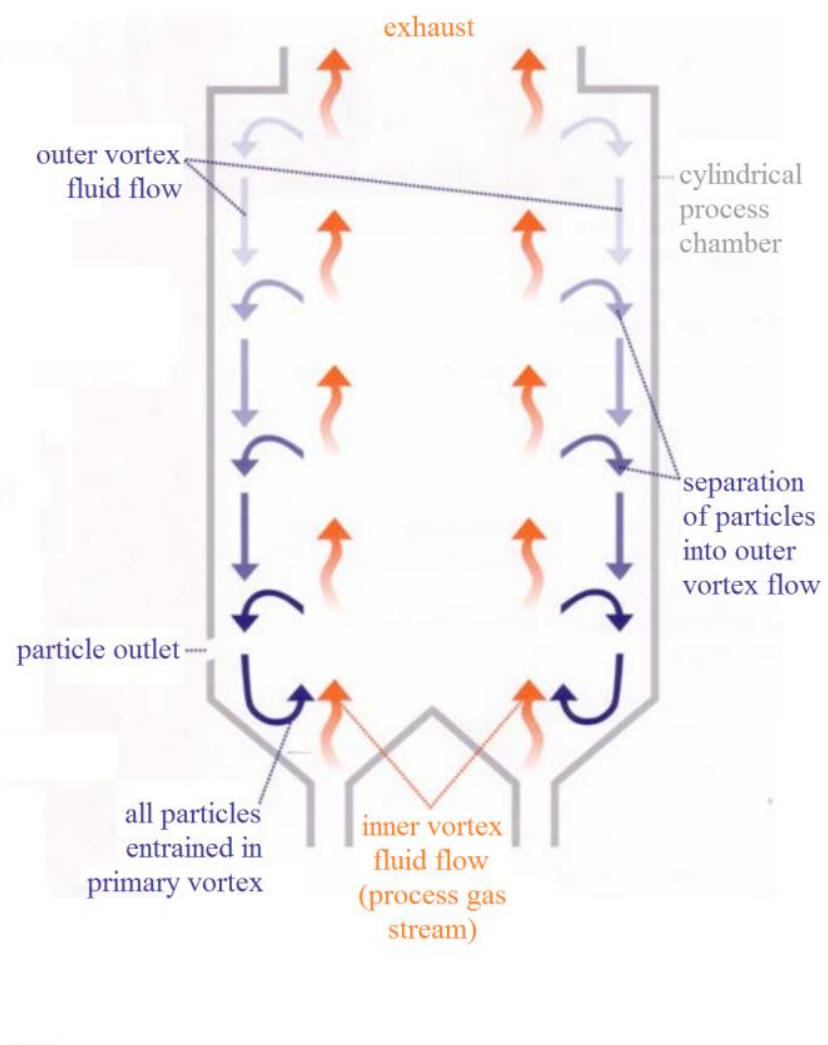

Figure 3. Schematics of the Torbed processes | (a) Compact Bed Reactor (CBR), and (b) Expanded Bed Reactor (EBR) - reproduced from Torftech literature

The CBR is a shallow bed design that uses inclined blades to impart tangential motion to the fluidising gas. The CBR generates a lower pressure drop across the bed compared to conventional fluidized beds, and is advantageous for short retention time processes (order of minutes and less) because of the small bed mass [33]. The EBR alternatively promotes both axial circulation of the particles at the periphery of the vessel and swirling around the annulus. This is achieved by using a tapered section between the distributor and outer wall such that cyclonic motion is also present. Here, particles are initially entrained by the process gas, resulting in them rising through the centre of the reactor. Then, due to centrifugal forces generated by their swirling motion, the particles move outwards towards the edge of the vessel before returning to the base to be entrained. The EBR is therefore a competitor to the circulating fluidized bed (CFB). Intensification is achieved in the EBR through enhanced mixing, hybridisation (integral reaction and cyclonic separation) and decreased reactor size to achieve a particular particle retention time.

The flow regimes of Swirling Fluidized Beds have been described according to both the pressure drop [6] and behaviour of the particle bed [34]. Design equations/models have also been proposed for the minimum swirling fluidization velocity [35,36,37], gas pressure drop [34,35] and transport velocity [35,37].

\subsection{Precedent for Industrial Carbon Capture and SWOT}

Laboratory scale applications of swirling fluidized beds have atse been investigated reported by Kuprianov et al. [38], Zhu and Lee [39], McQueen [40], Sundaram and Sudhakar [41], Dodson et al. [42], Farrell [43], Lee et al. [44] and Dodson [45]. A list of industrial case studies that have adopted the Torbed technology has also been compiled by Groszek and Laughlin [32]. Some of the main features of SFBs observed in these applications that are relevant to carbon capture include: low specific energy consumption, precise temperature control, isothermal operation, rapid heat/mass transfer, compact system, low pressure drop, low particle elutriation, processing of a wide range of particle sizes, independent adjustment of gas and solid residence times and uniform particle residence times. 
Regarding scalability, there is precedent for handling very high gas flow rates. For example, one of the industrial case studies described by Groszek and Laughlin [32] involved the removal of hydrogen fluoride from the exhaust gases of an aluminium smelter using the feed alumina material as a scrubbing agent. Around 1990, Comalco Aluminium Ltd installed 13 Torbed ${ }^{\circledR}$ reactors (6 m diameter) that could each treat $380,000 \mathrm{~m}^{3} / \mathrm{h}$ of gas using a single pass of the gas stream and alumina sorbent particles, producing HF and particulate emissions of $1 \mathrm{mg} / \mathrm{Nm}^{3}$. For comparison, the respective volumetric flow rates of the target $\mathrm{CO}_{2}$ sources from the cement and iron/steel sectors are $129 \mathrm{~m}^{3} / \mathrm{s}$ and $400 \mathrm{~m}^{3} / \mathrm{s}$, or $464,400 \mathrm{~m}^{3} / \mathrm{h}$ and 1,440,000 $\mathrm{m}^{3} / \mathrm{h}$, well within the total capacity of the established Comalco installation.

Table 6 shows the results of a SWOT (Strengths, Weaknesses, Opportunities and Threats) analysis applied to the Swirling Fluidized Bed (SFB) technology for the purpose of carbon capture based on the findings and observations of the aforementioned applications.

Table 6. SWOT Analysis Applied to a Swirling Fluidized Bed in the Context of $\mathrm{CO}_{2}$ Capture

\begin{tabular}{|c|c|}
\hline STRENGTHS & WEAKNESSES \\
\hline $\begin{array}{l}\text { - } \text { Of the SFB concepts being studied, the Torbed® } \\
\text { is already commercialized, and there are } \\
\text { numerous examples of the technology in various } \\
\text { industrial applications } \\
\text { - } \quad \text { High specific throughputs } \\
\text { High impact velocities and enhanced shear } \\
\text { around the particles promote intensified heat and } \\
\text { mass transfer rates } \\
\text { - Lower pressure drop compared to standard } \\
\text { fluidized bed technologies. High temperature } \\
\text { process gas can therefore be recirculated to } \\
\text { recoup energy savings } \\
\text { - Shallow particle beds allow rapid (real-time) } \\
\text { process control } \\
\text { The Torftech EBR can, it is believed, provide } \\
\text { higher particle retention times than their CFB } \\
\text { due to the longer circulation paths generated by } \\
\text { vertical swirling motion }\end{array}$ & $\begin{array}{l}\text { - Only a single commercial supplier of the } \\
\text { technology exists (Torftech Ltd.) } \\
\text { - Lack of 'open source'/standardised design } \\
\text { methodology } \\
\text { - Lack of a robust scale-up methodology (typically } \\
\text { requires pilot scale experimentation for proofs- } \\
\text { of-concept) } \\
\text { - Likely to see enhanced attrition of the adsorbent } \\
\text { particles }\end{array}$ \\
\hline OPPORTUNITIES & THREATS \\
\hline $\begin{array}{l}\text { Fine particles }(<50 \mu \mathrm{m}) \text { can be handled } \\
\text { compared to conventional fluidized beds, } \\
\text { enabling higher adsorbent surface area to volume } \\
\text { ratios to be used } \\
\text { Decoupling of the gas mass flow rate (or } \\
\text { volumetric flow rate) and fluidization velocity } \\
\text { might help alleviate the issue discussed in } \\
\text { Section } 4 \\
\text { The large surface area to bed volume ratio of the } \\
\text { distributor blades might provide a route for } \\
\text { achieving rapid heat transfer to the particle bed } \\
\text { The EBR would enable integrated adsorption and } \\
\text { cyclonic separation of the particles } \\
\text { Enhanced radial mixing could allow heat } \\
\text { exchange between the outer wall and the particle } \\
\text { bed }\end{array}$ & $\begin{array}{l}\text { Amine-based absorption using intensified } \\
\text { rotating packed beds (RPBs) } \\
\text { - A continuing move away from fossil fuel } \\
\text { combustion as an energy source } \\
\text { - Ultra-Low Carbon Dioxide Steelmaking } \\
\text { (ULCOS) } \\
\text { - OxyFuel technology in the cement sector for } \\
\text { carbon capture }\end{array}$ \\
\hline
\end{tabular}




\subsection{Stage Configurations and Solids Transfer}

The efficiency of a continuous TSA-based adsorption/desorption process using fluidized beds for $\mathrm{CO}_{2}$ capture is heavily dependent on the heat/mass transfer rates to the sorbent (discussed in Section 4.6), as well as the gas-solid contacting strategy. Ideally, countercurrent contact of the gas and sorbent is required to maintain the driving force for $\mathrm{CO}_{2}$ uptake, necessitating the use of multistage fluidized bed reactor models/designs [46]. Pirklbauer et al. [46] conducted a detailed thermodynamic analysis of the potential stage configurations for a dual fluidized bed system containing an amine-based sorbent and showed that the total energy demand (measured in $\mathrm{MJ} / \mathrm{kgCO}_{2}$ ) decreased as both the number of adsorber and desorber stages increased. They also showed that lean-rich sorbent heat exchangers become more effective at reducing the energy demand at higher numbers of adsorber and desorber stages. However, the true optimum configuration requires additional consideration of the capital cost; additional sorption stages and sorbent heat exchangers decreases the OPEX at the expense of CAPEX. This compromise between OPEX and CAPEX may be more sensitive in the toroidal fluidized bed because of the enhanced heat/mass transfer and increased cost of the angled blade distributor compared to a conventional distributor.

For continuous adsorption and desorption using fluidized beds, circulation of the sorbent between beds is achieved by operating the beds in the pneumatic transport regime, where the gas velocity is sufficient to entrain the particles. The gas and particles can be subsequently separated in a cyclone, allowing the captured sorbent to be delivered to the other bed [47], creating a sorbent circuit. The individual fluidized bed stages themselves can be separated using finely perforated plates, with movement of the particles between stages facilitated by downcomers [48].

It has been shown that the pneumatic transport gas velocity in swirling/toroidal fluidized beds is substantially higher than in conventional fluidized beds [37] because the gas momentum is mainly directed in the radial and tangential direction. Nevertheless, these beds can still be configured to transport and separate the solids using the same pneumatic transport/cyclone separator approach as the circulating fluidized bed $[37,38,39,45]$. The main difference is the toroidal fluidized bed also promotes additional swirling motion during the particle rise, which increases the contact time between the gas and solid phases whilst delivering better heat/mass transfer. Regarding inter-stage sorbent transfer, the solid particles can be injected toward the centre of the bed and extracted at the outer periphery because of the outward motion of the particles generated by centrifugal force. This configuration is mentioned in the list of case studies described by Groszek and Laughlin [32], and a sketch of the concept is included in Figure 4.

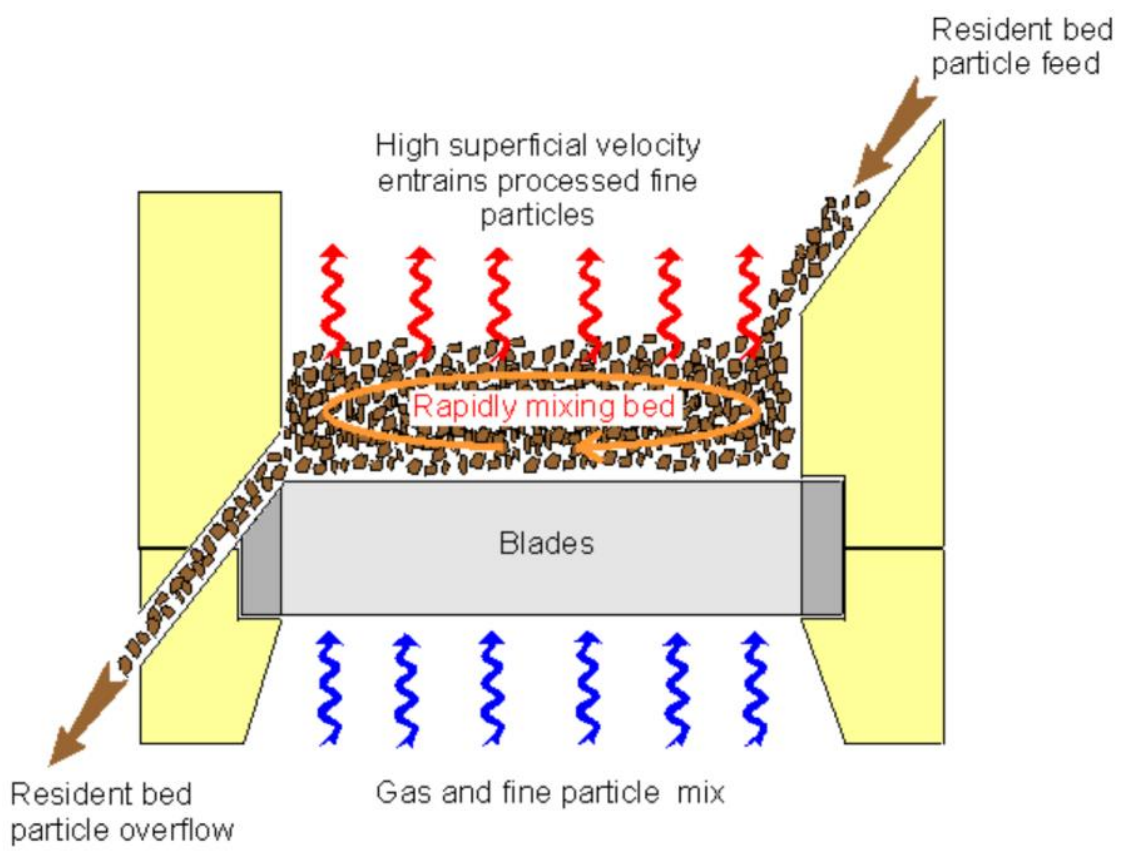

Figure 4. Sketch of particle extraction from the outer periphery of a toroidal fluidized bed [32, 42] 


\subsection{Current Progress on Heat Transfer in Toroidal Fluidized Beds}

Initially, Newey and Howard [9] investigated the use of a partitioned oval-shaped fluidized bed as a gas-togas heat exchanger that used angled distributor blades to promote the flow of a particle bed around a complete circuit, akin to a form of rotating regenerator (known as the 'racetrack'). Described in a Patent [49], the particles acted as an intermediary between the hot and cold gas streams fed on to opposite sides of the partition. The authors characterised the heat transfer with an effectiveness factor defined as the ratio of actual heat transfer rate between the streams to the heat transfer rate obtainable from an exchanger with perfect parallel-flow under the same inlet conditions. The effectiveness was highest for shallower beds with low hot stream gas velocities and high cold stream gas velocities. Cross-contamination of the hot and cold streams could purportedly be controlled by adjusting the partition gap size (used for exchanging solids between the hot and cold side) and by applying a pressure differential of $600 \mathrm{~Pa}$ between the hot and cold side freeboard regions. However, the cross-leakage of 10-40\% would make this configuration in its current form unsuitable for carbon capture and sorbent regeneration.

Lu et al. [50] later determined the heat transfer coefficients between submerged heating cylinders and the particle bed in a rectangular SFB. Their rectangular chamber had a width, length and height of $457 \mathrm{~mm}, 584$ $\mathrm{mm}$ and $1192 \mathrm{~mm}$ respectively. Fluidization was achieved via vertical gas distributors placed below the bed, while 12 secondary air injection nozzles (three per corner) generated the swirling motion. Based on previous literature for fluidized beds, Lu et al. [50] showed that two simple correlations could reasonably predict the maximum value of the heat transfer coefficient between the bed and heaters (errors of $<12 \%$ ) for particle diameters of $0.359-0.718 \mathrm{~mm}$ (equation 1 [51]) and $0.18 \mathrm{~mm}$ (equation 2). In these equations, $\rho_{\mathrm{p}}$ is the particle density, $\mathrm{k}_{\mathrm{g}}$ is the gas thermal conductivity, $\mathrm{d}_{\mathrm{p}}$ is the particle diameter and $\rho_{\mathrm{sb}}$ is the bulk density of the bed. Similar to data in [6], $\mathrm{Lu}$ et al. [50] observed that $\mathrm{h}$ decreased at increasing heights above the distributor. They also noted that $\mathrm{h}_{\max }$ occurred for gas velocities between 1.5-3 times the minimum fluidization velocity.

$$
\begin{aligned}
& h_{\max }=35.8 \rho_{p}^{0.2} k_{g}^{0.6} d_{p}^{-0.36} \\
& h_{\max }=120.8 \ln \left(7.05 \times 10^{-6} \frac{\rho_{s b}}{d_{p}}\right)
\end{aligned}
$$

\subsection{Potential Heat Transfer Solutions}

Heat transfer to the particle bed is critical for the design of the regeneration system. However, as shown in the previous section, there are very few published results concerning the heat transfer characteristics of the Torbed (or other SFB variants), which might hinder the design of a large-scale SFB carbon capture process. An additional challenge is the need to minimise any energy penalties associated with the regeneration of the sorbent. For instance, although hybrid fluidized bed drying technologies analogous to sorbent regeneration exist (e.g. microwaves, ultrasonication and infrared lamps) [84] (Sivakumar et al., 2016), these require additional energy input that would increase the parasitic load of the carbon capture system. The three main practical approaches for delivering thermal energy to the particles that are compatible with the waste heat sources identified in Table 3 are via: (1) thin-walled heat transfer surfaces immersed in the bed, (2) wall-bed heat transfer, and (3) direct gas-solid heat exchange, whose characteristics are discussed below.

As identified by Ramshaw et al. [52], the heat transfer coefficient around a tube in a gas stream can be increased by an order of magnitude using a fluidized bed (compared to gas flow alone) because the particles facilitate the transport of sensible heat directly from the boundary layer. However, Botterill et al. [53] have also shown that there is a significant heat transfer performance deficiency at the top and bottom of circular tubes submerged in conventional fluidized beds. This is because above the tube there exists a de-fluidized particle zone, whilst below the tube there is a particle-free zone. In the SFB heat transfer study conducted by Lu et al. [50], the circumferential heat transfer characteristics of the submerged heaters was not measured. Nevertheless, it can be inferred from Botterill et al.'s observations [53] that a circular tube will presumably produce a de-fluidized wake that will be orientated according to the angle of the swirling gas. Further, there is a limit to the maximum heat transfer rate using circular tube bundles because the particle motion will eventually become hindered if the tube packing density is too high [54]. To eliminate the deficiency zones obtained with circular tubes, Ramshaw et al. [52] proposed the use of thin hollow slats that can be assembled 
in a matrix array using simple support rods (Figure 5a). Thus, the same principle can be extended to the toroidal fluidized bed. Figure 5b shows a sketch of a theoretical arrangement to maximise heat transfer and minimise gas pressure drop and dead-zones, while Figure 5c shows a sketch of a potential multi-stage configuration using the same concept. Here, the angled slats would help to compensate for the loss of angular momentum from the gas-solid interaction, at the expense of higher pressure drop.

(a)

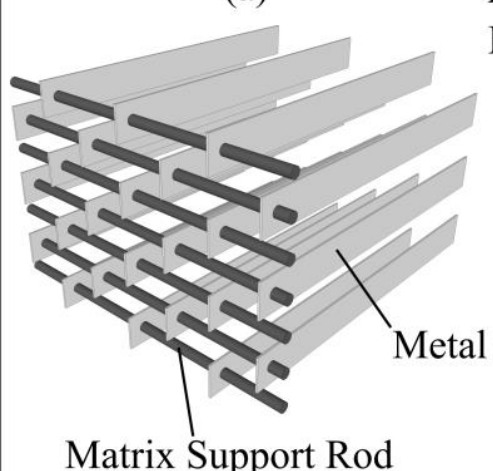

Angled Heat

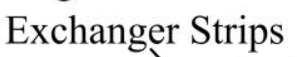

(b)

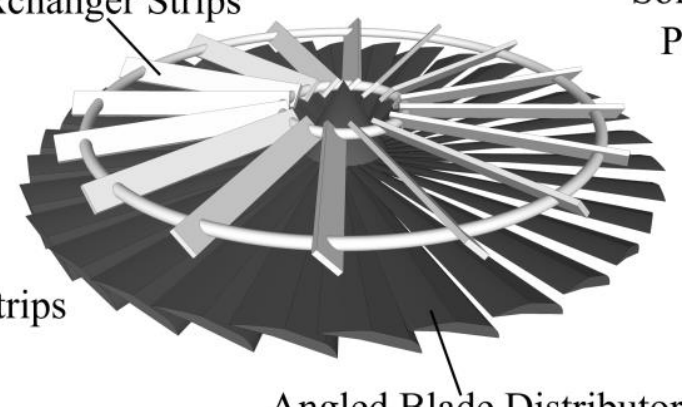

(c)

Solids

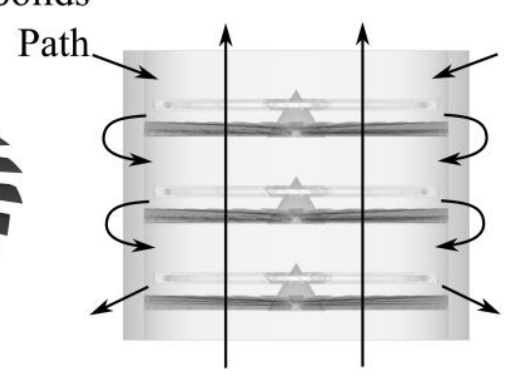

Air Path

Figure 5. (a) Sketch of a fluid bed heater matrix for use in shallow fluidized beds (adapted from [52,55]), (b) sketch of an angled hollow slat structure in a toroidal fluidized bed, (c) sketch of a countercurrent multistage toroidal fluidized bed regenerator using immersed hollow slats

In addition to transferring heat from immersed surfaces, the toroidal fluidized bed also presents an opportunity to transfer heat from the peripheral wall, via integrated heat exchangers, to the particles. Heat transfer between the exterior wall and the particles has been studied in conventional fluidized beds as a model system for understanding the wall-particle heat transfer dynamics [56,57]. Further, it has been shown that the temperature profile across the bulk particles in a wall-cooled fluidized bed is flat [58], implying sorbent regeneration could be uniform. However, steep thermal boundary layers are also observed in close proximities to the walls in conventional fluidized beds [58]. It is envisaged that these thermal gradients can be minimised in the toroidal fluidized bed to enable practical extraction of sensible heat from the wall because of the enhanced radial mixing. This is because the axial momentum of the particles is converted to radial and tangential momentum by the swirling gas phase [59]; the resulting centrifugal forces draw particles towards the outer wall to accelerate heat transfer in the wall region. Precedent for rapid heat transfer and uniform bed temperatures has been demonstrated in a number of swirling fluidized bed studies $[60,61,62]$. Wall-integrated heat exchangers would advantageously minimise disturbances to the particle mixing, and would be simpler/cheaper to construct than immersed heat transfer surfaces. However, the effectiveness might diminish for increasing bed diameters, meaning this approach might be better applied in combination with immersed heat transfer surfaces.

Finally, the thermal energy for sorbent regeneration could be taken from the fluidization/sweep gas itself in a direct gas-solid heat exchange process, the main precedent being fluidized bed dryers, which are already established as an industrial application. This approach would involve convective/radiative heat transfer from the gas phase to the solid followed by subsequent conduction within the solid to supply the thermal energy required for sorbent regeneration. In conventional fluidized beds, the convective, radiative and conductive heat transfer mechanisms can be approximated as being separate and additive [63], though radiation will be negligible for the temperatures below $500 \mathrm{~K}$ for particle diameters around $500 \mu \mathrm{m}$ [64]. The convective heat transfer coefficient is a function of the Archimedes and Prandtl numbers, and the overall heat transfer coefficient typically undergoes a maximum when increasing particle size [63]. This is because of the changing influences of conduction and convection. Although smaller particles produce smaller conductive thermal resistances, these fine particles $(<10 \mu \mathrm{m})$ typically agglomerate and produce gas channelling that reduces the effectiveness of convection. One of the main benefits of toroidal fluidized beds in this regard is high gas velocities can be used without particle elutriation, meaning higher convective heat transfer coefficients could be attainable; a heat transfer coefficient as high as $8 \mathrm{~kW} / \mathrm{m}^{2 \circ} \mathrm{C}$ has been reported for vermiculite exfoliation [65]. Further, this method does not disturb the fluidization process, meaning the attrition rates will likely be smaller than the proposed configuration shown in Figure 5b. One potential pitfall 
is whether the waste process gas (Table 3) is clean enough to be used directly in the fluidized bed; this may necessitate a preliminary gas-to-gas heat exchanger that will increase energy losses and therefore reduce the overall capture efficiency.

Ultimately these concepts are speculative, and therefore require experimental validation in order to assess their feasibilities. Thus, it is highly recommended for future toroidal fluidized bed studies to focus on these heat transfer configurations. In particular, it is essential to produce reliable/robust correlations that describe the heat transfer rate from immersed surfaces, the walls and the fluidizing gas to the particles that can be used for design. Furthermore, careful consideration of the particle residence time distribution is required, because highly variable residence times would lead to non-uniform regeneration of the sorbents, which is one of the reported challenges of analogous continuous fluidized bed dryers [66].

\section{Regenerating Bed Design and Heat Recovery Considerations}

The concept of using direct air-solid heat transfer is appealing because it minimises the complexity of the regeneration unit. However, it is highly unlikely that a fluidized bed (standard or toroidal) using nitrogen, or air, or other process gas as the fluidising gas will be used for regeneration of the sorbent as this will lead to a high degree of dilution of the $\mathrm{CO}_{2}$ desorbed from the sorbent because a similar volumetric flow rate to the adsorber would be needed to maintain fluidisation. Therefore, it is envisaged that the regenerating bed will be either a fixed or moving bed (low gas flow rates, high levels of concentration) or, alternatively, will make use of superheated steam as a sweep/fluidising gas. This would potentially allow the use of a fluidized bed with high transport rates (relative to fixed/moving beds). One potential problem with this idea is that the superheated steam may not be chemically inert to the sorbents synthesised during this project. However, Coenen et al. [67] report that the cycling working capacity of potassium-promoted hydrotalcites increases when using steam for regeneration, because steam is able to regenerate certain sites whereas nitrogen cannot. Additionally, Wood et al. [68]; used superheated steam to regenerate hydrotalcite-type sorbents in a fixed bed regenerator suggesting that one could also use superheated steam to regenerate hydrotalcites in a fluidized bed configuration. Finally, in their thermodynamic analysis, Pirklbauer et al. [47] showed that superheated steam produced a lower energy penalty for regenerating an amine-functionalized solid sorbent compared to regeneration in a pure $\mathrm{CO}_{2}$ stream when using TSA.

The means of recovering/providing heat to the regenerator for each idea is as follows:

- Fixed/moving bed. It is envisaged that the main supply of heat to the bed will be via heat transfer tubes (or similar) submerged within the bed (similar to the designs discussed in Section 4.6). The relatively small gas flow to the sorbents will also be pre-heated. The heating medium for both the gas pre-heater and the heat transfer tubes will be process steam. Hence, a waste-heat boiler will be used to raise steam (using waste heat from heat source) that will then be used for regeneration.

- $\quad$ Fluidized bed using superheated steam. The superheated steam will be used as the fluidising/sweep gas and the heating medium to the bed. In this scenario, the super-heat will provide the heat of desorption to the sorbent without any condensation. The $\mathrm{CO}_{2}$ will desorb into the steam sweep/fluidising gas and the steam will be condensed downstream of the bed, to produce a pure $\mathrm{CO}_{2}$ stream and saturated water. Hence, a waste heat boiler and super-heater will be required to recover waste heat from the heat source. It is envisaged that the steam will be relatively low pressure with a relatively high superheat (similar to that employed in superheated steam dryers which is often also generated using waste heat - see [69] for examples). Superheated steam has also been investigated in fluidized bed dryers [70].

In both cases, the primary means of waste heat recovery will be via a waste heat boiler that is a wellestablished technology employed throughout the process industries. It is also worth mentioning that direct and indirect heating for regeneration is technically applicable to both fixed/moving beds and fluidized beds. However, direct heating of the moving bed with a sweep gas would necessitate a minimum flow rate to ensure a good heat transfer rate with the bed. This would dilute the captured $\mathrm{CO}_{2}$ resulting in poorer capture efficiency, meaning the use of indirect heating via heat transfer surfaces in the bed would be the preferred approach. 


\section{Proposed $\mathrm{CO}_{2}$ Capture Configurations 6.1 Cement}

Cement is produced from calcium carbonate $\left(\mathrm{CaCO}_{3}\right)$ via a three-stage process. First, the raw materials (limestone, aluminium oxides, silicon oxides and iron) are grinded and blended before being pre-heated in a suspension pre-heater using exhaust combustion gases from the rotary kiln. Here, the limestone undergoes its initial calcination. In some plants, a dedicated pre-calciner heated by exhaust gases from the kiln and a secondary burner is also used. Following pre-heating (and pre-calcination), the mixture of limestone and corrective additives enters a rotary kiln, where it undergoes further reduction to produce lime $(\mathrm{CaO})$. The heat required for the reaction is supplied by combusting pulvarised coal (or another fuel) directly in the kiln [71]. The rotary kiln itself typically comprises four main stages: (i) dehydration $\left(20-900^{\circ} \mathrm{C}\right)$, (ii) calcination $\left(850-950^{\circ} \mathrm{C}\right)$, (iii) clinkerisation and partial melting $\left(1200-1450^{\circ} \mathrm{C}\right)$, and (iv) cooling $\left(1350-1200^{\circ} \mathrm{C}\right)$, to allow for crystallisation of calcium aluminate and calcium ferrite from the partial melt [72] The clinker emerging from the kiln is then cooled using air before being stored prior to distribution or cement preparation. The final cement product is obtained by combining and milling the clinker with gypsum and other mineral compounds.

There are four different integrated process routes used for the production of cement, differentiated by the moisture content of the raw materials entering the kiln. These are the wet process, semi-wet process, semidry process and dry process. These processes have respective fuel consumptions of $5000-7000 \mathrm{~kJ} / \mathrm{kg}, 3500$ $5000 \mathrm{~kJ} / \mathrm{kg}, 3500-5000 \mathrm{~kJ} / \mathrm{kg}$ and $2750-4000 \mathrm{~kJ} / \mathrm{kg}$ of clinker [72]. Initially, cement production processes used water to create slurries to improve the homogenisation of the raw materials blend. However, the production of clinker has evolved towards the dry process, as technological developments have made it possible to produce homogeneous dry blends [72]. Over 90\% of cement production operations in Europe employ the dry process [73]. Its main advantage is less waste heat associated with the dehydration of the raw materials.

The rotary kiln is the single largest emitter of $\mathrm{CO}_{2}$, where $\mathrm{CO}_{2}$ is produced both as a combustion product (usually from coal) and from the calcination of limestone [71]. The flue gas produced by the kiln is often directed through the pre-calciner and suspension pre-heater before reaching the stack. Thus, any $\mathrm{CO}_{2}$ emitted during preliminary processing are also emitted from the same single source [73]. The total mass of emitted $\mathrm{CO}_{2}$ from this stack amounts to 0.8 tonne per tonne of clinker, based on a study of average emissions from the UK cement sector [75]. Thus, the stack is the obvious target for the development of the hydrotalcite adsorbents.

Waste heat is abundantly available in cement plants, as there is a lack of heat sinks in a suitable temperature range for conventional waste heat recovery [76]. Khurana et al. [48] concluded that up to $35 \%$ of heat in a cement plant is lost as unrecovered waste. This is outlined in the Sankey diagram in Figure 6. These data were verified by a more recent investigation into industrial waste heat recovery by Element Energy et al. [12]. 


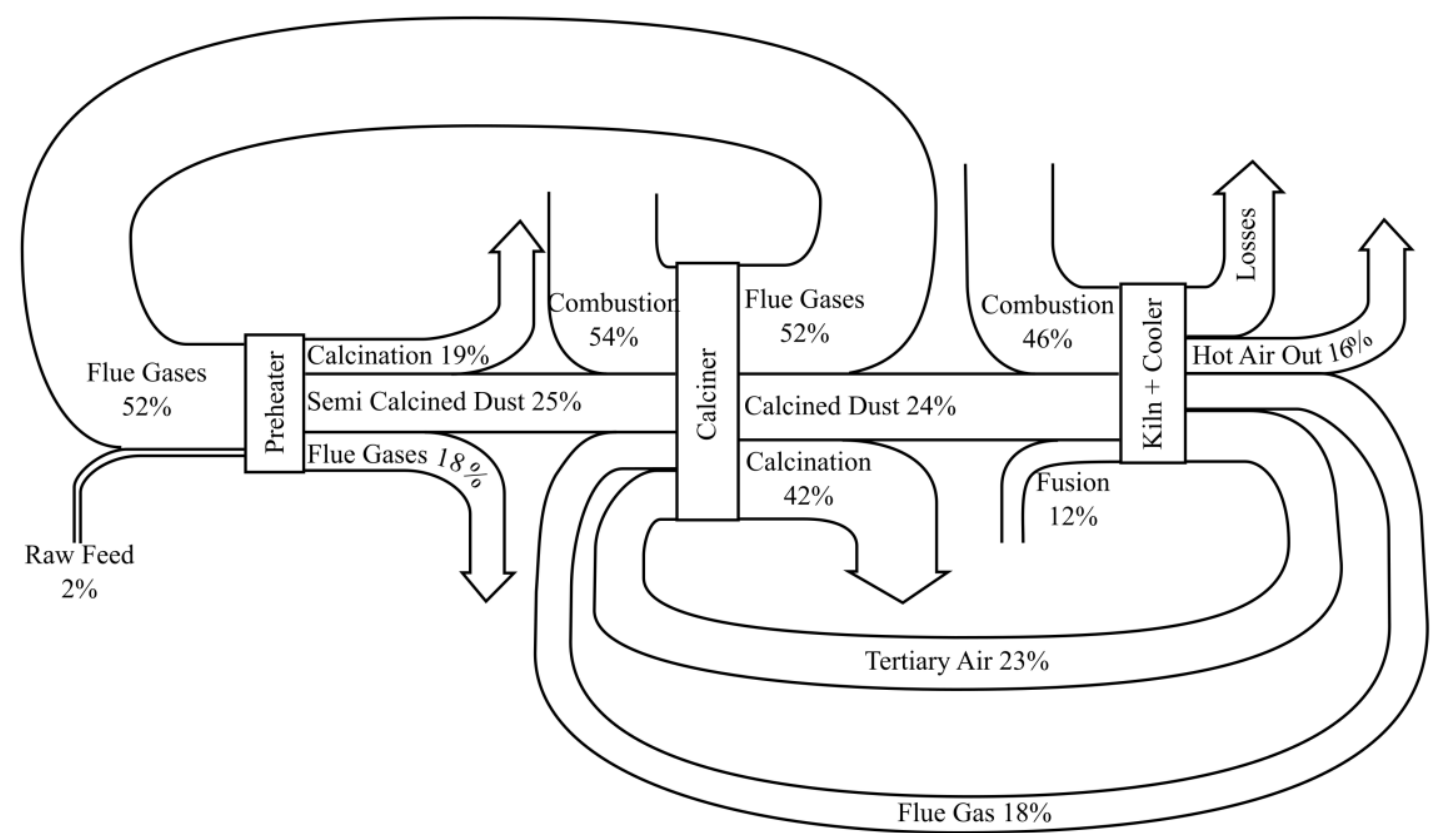

Figure 6. Sankey diagram for a typical cement plant [77]

For this project, the waste heat provided by the cooler exhaust has been deemed to be the best option for the temperature swing regeneration process. This waste heat stream has a source temperature of $400^{\circ} \mathrm{C}$ [12], which would provide a $220-320^{\circ} \mathrm{C}$ temperature swing between the carbon source (stack gas) and heat source before any pre-cooling of the carbon source is considered. With $568 \mathrm{~kJ}$ of heat available per $\mathrm{kg}$ of clinker, this is the second-most abundant heat source, just $10 \%$ lower than the largest heat source (pre-heater exhaust) [12]. Importantly, the cooler exhaust is not integrated into the process like the pre-heater exhaust gas. This means it is not emitted via the common stack (main $\mathrm{CO}_{2}$ source), making it available for heat recovery. Although outside the scope of the present project, future work could also evaluate the potential of recovering heat from the pre-heater exhaust as well. This might be advantageous should the stack gas require cooling prior to carbon capture (e.g. depending on the sorbent requirement), because it would reduce the amount of cooling duty required.

Figure 7 outlines the proposal of the present project to capture $\mathrm{CO}_{2}$ from the main stack of a cement plant employing the dry process with pre-calcination via a dual fluidized bed system. Here, regeneration of the sorbent is achieved using superheated steam (raised using the waste heat from the cooler exhaust). Following cooling and condensation of the steam, an almost pure stream of $\mathrm{CO}_{2}$ will be captured, avoiding the aforementioned dilution problem encountered with dual fluidized beds (see Section 4). Technical challenges to address with the Swirling Fluidized Bed reactor in this project are the potential cross-leakage of the gases between the two beds, sorbent attrition, and optimisation of the contacting strategy (balancing mixing intensity vs contact time). 


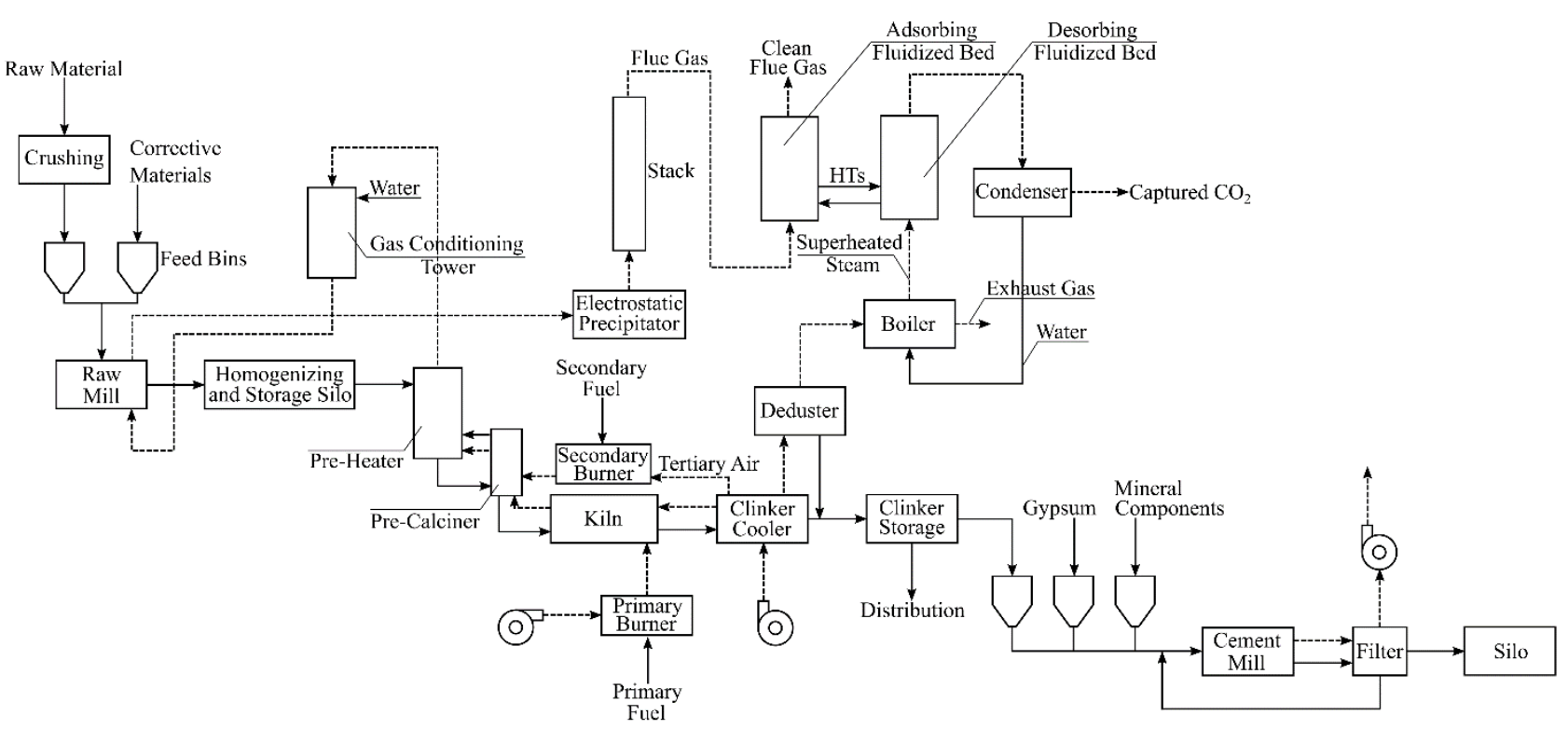

Figure 7. $\mathrm{CO}_{2}$ capture from the stack gas produced in the dry-cement process with pre-calcination with sorbent regeneration achieved using superheated steam raised from the waste heat from the clinker cooler exhaust $\mid$ adapted from the schematic of the dry process with pre-calcination reported by the IEA [72]

\subsection{Iron \& Steel}

Iron and steel are produced from a combination of iron ore, limestone and coal in a three-step process: (i) raw materials preparation, (ii) iron making and (iii) steel making. The main routes for iron manufacture are via the blast furnace, smelt reduction or direct reduction, whilst the two main routes for steel are the basic oxygen furnace and electric arc furnace [78]. Carpenter [79] outlines these technologies in detail. For the purpose of this project, the integrated blast furnace-basic oxygen furnace route is considered. In the blast furnace, sintered iron ore pellets are reduced using carbon monoxide (created from the oxidation of coke) to form pig iron with 93-95\% iron content; the limestone's purpose is to remove sulphur and other impurities. In the basic oxygen furnace, the pig iron (along with scrap iron) is contacted with oxygen to reduce the carbon content to $1 \%$ and remove impurities [77]. This is followed by ladle metallurgy (addition of alloying elements such as chromium and nickel) and casting/rolling.

Emission of $\mathrm{CO}_{2}$ from the iron and steel sector is complicated by the wide range of $\mathrm{CO}_{2}$ sources, some of which are already highly integrated in waste-heat recovery circuits, thereby shifting the points of emission. Off-gases are produced by the coke oven (COG), blast furnace (BFG) and basic oxygen furnace (BOFG). Approximately $70 \%$ of the COG is used in various unit operations for the production of iron and steel; 15\% is recycled back into the coke oven whilst a further $\sim 15 \%$ is used for steam raising in the power plant [80]. The remainder of the $70 \%$ is presumably used to heat the sinter plant/lime kiln and pre-heat the air fed to the blast furnace. Surplus COG is usually flared or emitted directly to the atmosphere [81]. The BFG, containing $17-25 \% \mathrm{CO}_{2}$, is usually used as a fuel in both the blast furnace stove and coke oven, with the remainder used in the power plant for onsite steam and electricity generation [79]. Finally, the BOFG is still typically flared at many sites owing to its intermittent generation, variations in temperature and varying concentrations of $\mathrm{CO}(55-80 \%)$ and $\mathrm{N}_{2}(8-26 \%)$. Some producers of steel already capture and use the BOFG; however, the main challenge for recovering this waste heat via a retrofit are the high capital costs and difficulties emerging from the use of hot dirty gases $[79,82]$.

For the basis of this project, it is assumed that the preferred point of capture would be from the points of emission, therefore minimising disruption to the process and the complexity of the retrofitting operation. It is assumed that this will increase the attractiveness of the carbon capture solutions developed within this project. Based on data available in the literature [83], the power plant stack was subsequently identified as the target carbon dioxide source for development of the hydrotalcite adsorbents, as it is the largest point of emission and also the most potent source of $\mathrm{CO}_{2}$ (concentrations up to $28 \%$ ). For this project, only gaseous waste heat sources are considered because the residual heat in the molten iron/steel (or other solid sources) 
are assumed to present an insurmountable recovery challenge within the scope of this project. See Carpenter [79] for a brief discussion for the waste heat recovery from slag. The basic oxygen furnace (BOF) off-gas has been selected for this project as the primary heat source for sorbent regeneration because it presents the highest temperature and enthalpy [11] and has the least existing integration into the iron/steel process (compared to COG and BFG).

Figure 8 presents a schematic of an integrated iron/steel mill with the proposed post- $\mathrm{CO}_{2}$ capture achieved via a dual fluidized bed system using superheated steam for sorbent regeneration (again to avoid the dilution problem outlined in Section 4). Here, the superheated steam is raised using the waste heat recovered from the BOF off-gas. The same technical challenges as identified in Section 5.1 must be considered. There is minimal scope to extend this concept to processes using the electric arc furnace (EAF) because this waste heat is typically already used for the pre-heating of scrap steel.

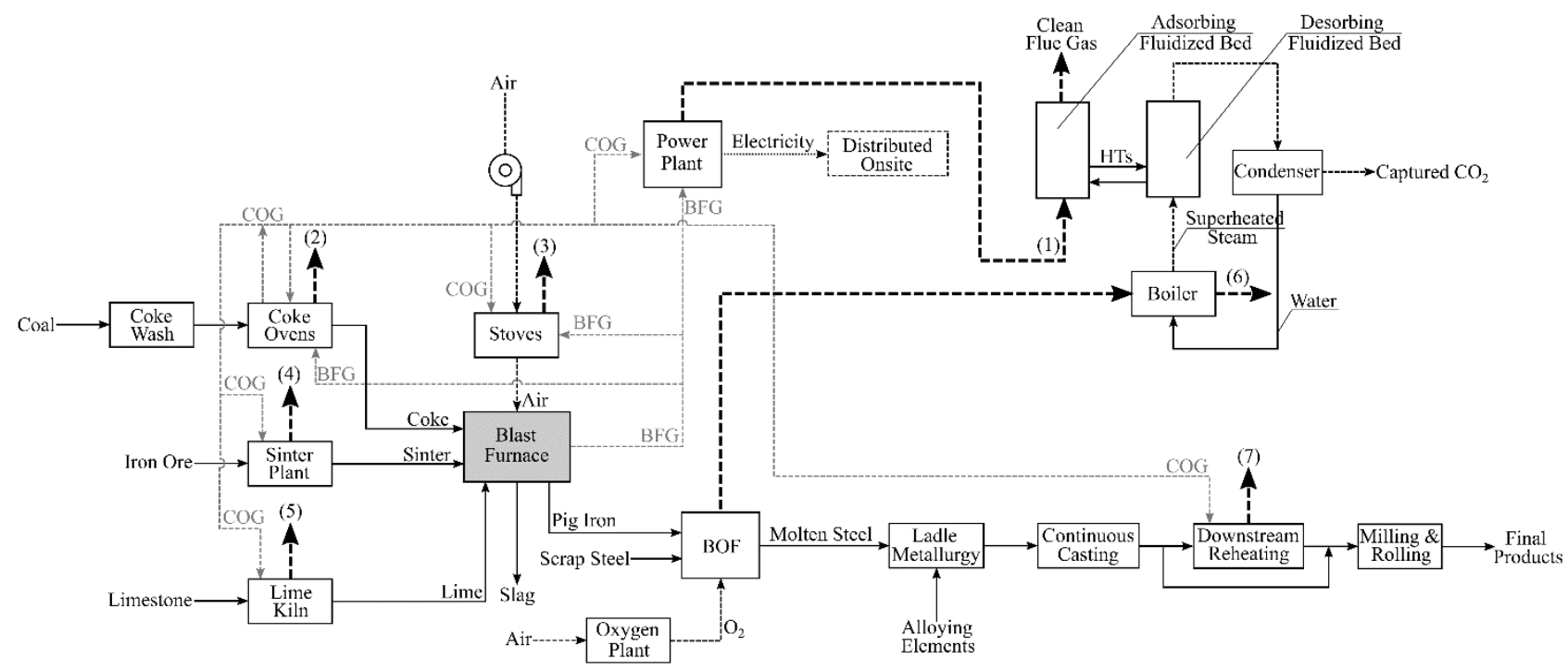

Figure 8. $\mathrm{CO}_{2}$ capture from the power plant stack from an integrated iron/steel mill with sorbent regeneration achieved using superheated steam raised from the waste heat from the BOF off-gas (COG= Coke Oven Gas, BFG = Blast Furnace Gas, BOF = Basic Oxygen Furnace, BOFG = Basic Oxygen Furnace

Gas)| based on the schematic for a conventional integrated steel mill reported by Ho et al. [78]

\section{Experimental Testing of the Concept}

The prospect for capturing $\mathrm{CO}_{2}$ from industrial sources (mainly cement and iron/steel) will be evaluated in this EPSRC collaboration through the implementation of four work packages:

- $\quad W P 1$. Synthesis and screening of novel, tailored and low-cost hydrotalcites

- WP2. Process intensification of a combined energy-efficient unit for capture

- WP3. Process modelling and simulation of the adsorber and the carbon capture process

- WP4. Whole system integration, technical, economic and environmental assessment of the proposed technology

The bulk of the experiment work at Newcastle University is focussed on WP2, i.e. the development of an intensified unit for $\mathrm{CO}_{2}$ capture and sorbent regeneration. The main experimental objectives are (i) to install and optimise the use of a 3D printer to manufacture/assemble micro-scale testing rigs, (ii) investigate the hydrodynamics of novel micro-/mini-fluidized bed designs, (iii) screen the adsorption and desorption performance of different hydrotalcite materials in different fluidized bed configurations under operating conditions equivalent to industrial conditions, and (iv) commission the use of a pilot-test facility for the screening of hydrotalcite materials at larger scales (up to $100 \mathrm{~kg} / \mathrm{h}$ ). A brief overview of the present methodology is described below. 


\subsection{D Printing (Additive Manufacturing) of Novel Mini-Fluidized Beds}

All milli/micro-scale fluidized beds and small scale swirling fluid bed reactors are being fabricated via additive manufacturing using the stereolithographic (SLA) approach in a Form2 (FormLabs) 3D printer. Stereolithography involves the layer-by-layer construction of prototype parts through the photopolymerisation of a resin. The Form 2 uses a $405 \mathrm{~nm}$ UV laser $(140 \mu \mathrm{m}$ spot size, $250 \mathrm{~mW})$ to cure a transparent methyl acrylate based proprietary resin (FLGPCL02) comprising methyl acrylate monomers (55$75 \% \mathrm{w} / \mathrm{w})$, methyl acrylate oligomers $(35-40 \% \mathrm{w} / \mathrm{w})$ and photo-initiator additives $(10-15 \% \mathrm{w} / \mathrm{w})$. Construction of each layer involves the laser scanning quickly through the resin tank according to the shape defined by the corresponding slice through the geometry, adhering the new layer to the previous layer. The Form2 delivers a maximum XY (horizontal) resolution of $150 \mu \mathrm{m}$ and Z-axis (vertical) resolutions of 25-100 $\mu \mathrm{m}$. Examples of novel fluidized bed designs currently being tested in this project are shown in Figure 9 below.

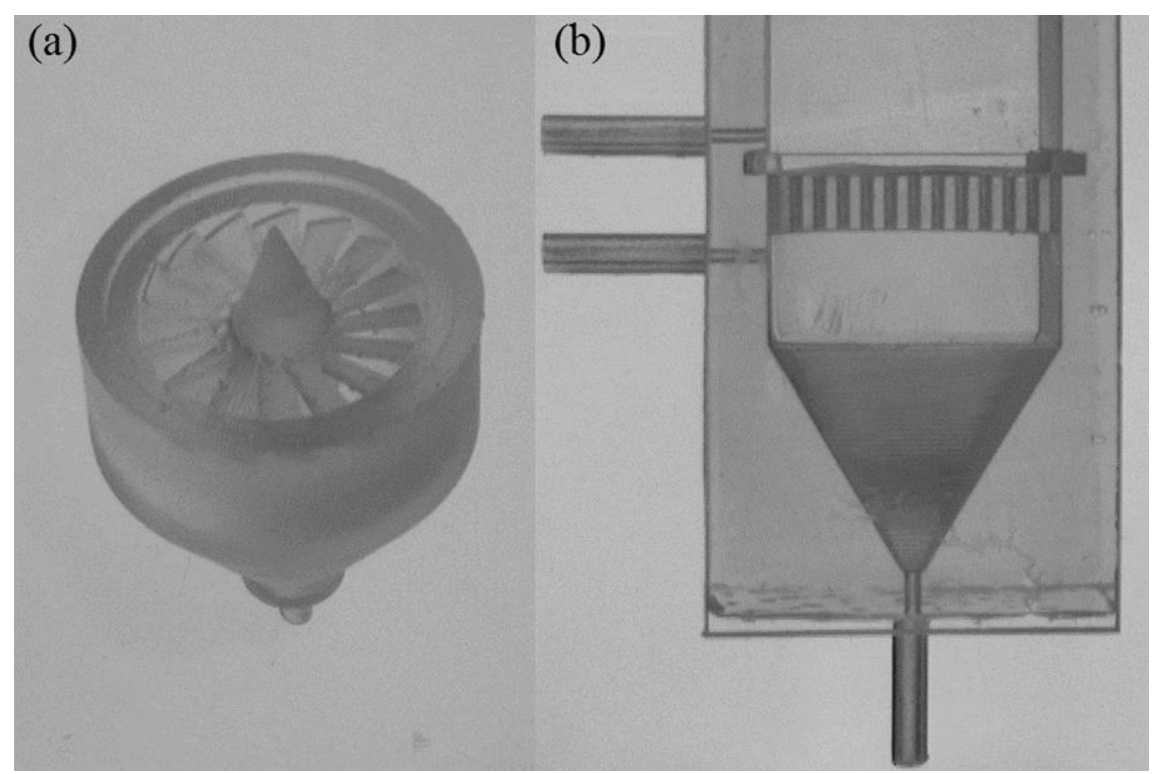

Figure 9. Novel 3D printed fluidized bed samples $\mid$ (a) mini swirling gas distributor, (b) mini planar gas distributor $(25 \times 25 \mathrm{~mm}$ cross-section) with pressure measurement ports above and below the distributor

\subsection{Flow Regime Mapping of Mini-Scale Fluidized Beds}

The purpose of the hydrodynamics investigation is to produce a flow map that identifies the minimum fluidization, minimum bubbling and slugging velocities based on particle size, bed height, bed size, gas flow rate, etc. Producing such a flow map will allow the small-scale carbon capture experiments to be performed in a non-mixing limited regime to ensure the underlying kinetics are observed (slugging would likely be detrimental to mixing performance, and therefore $\mathrm{CO}_{2}$ uptake for example). The hydrodynamics investigation is being conducted in various scaled 3D printed fluidized beds. Characterization of the bed designs is achieved via high-speed imaging and pressure drop measurements. Details of the approach along with preliminary results are described below.

The fluidized beds can be filled with either silica or glass beads (densities of 2.65 and $2.5 \mathrm{~g} / \mathrm{cm}^{3}$ respectively) with particle diameters of 75-180 $\mu \mathrm{m}$ and bed heights ranging from 6-100 $\mathrm{mm}$. Gas distributor channels are integrated into the beds and fitted with fine mesh screens ( $26 \mu \mathrm{m}$ aperture) to support the static particle bed. Glass wool packed below the distributor also assists in the prevention of gas maldistribution. The fluidizing gas is compressed air regulated to 1 bar using an AW4000 regulator; the flow rate is controlled via a series of Omega float meters, ranging $0.4-4000 \mathrm{~mL} / \mathrm{min}$. High speed imaging of the fluidized beds is performed using a Basler acA1300-200uc camera (169 fps, 1.3 MP) fitted with a COSMICAR Television lens (12.5 mm, 1:14), and is monitored via Pylon Viewer software. The bed is illuminated with an LED light panel and fibre optic directional lamp (Microlight 150). Custom pressure ports are also integrated into each printed bed at different positions around the distributor and gas exit (examples in Figure 6b). A Druck LP1000 series ultralow different pressure transducer (LPX1012-C1S-1) enables the pressure drop between any two of these 
ports to be measured in the range of -1 to +1 mbar. A PicoScope system monitors the pressure transducer at its maximum response rate of $10 \mathrm{~ms}$ in order to capture the dynamics of emerging gas bubbles in the bed.

Figure 10 shows several still image samples recorded from the high-speed camera in a $5 \times 25 \mathrm{~mm}$ fluidized bed containing $93 \mu \mathrm{m}$ silica particles. These images show the progression of more intense bubbling behavior as the gas velocity is increased. The range of flow rates in these images covers the optimal working range of the $\mathrm{CO}_{2}$ analyzer that will be used for in situ measurements during the hydrotalcite screening experiments (see Section 6.3).

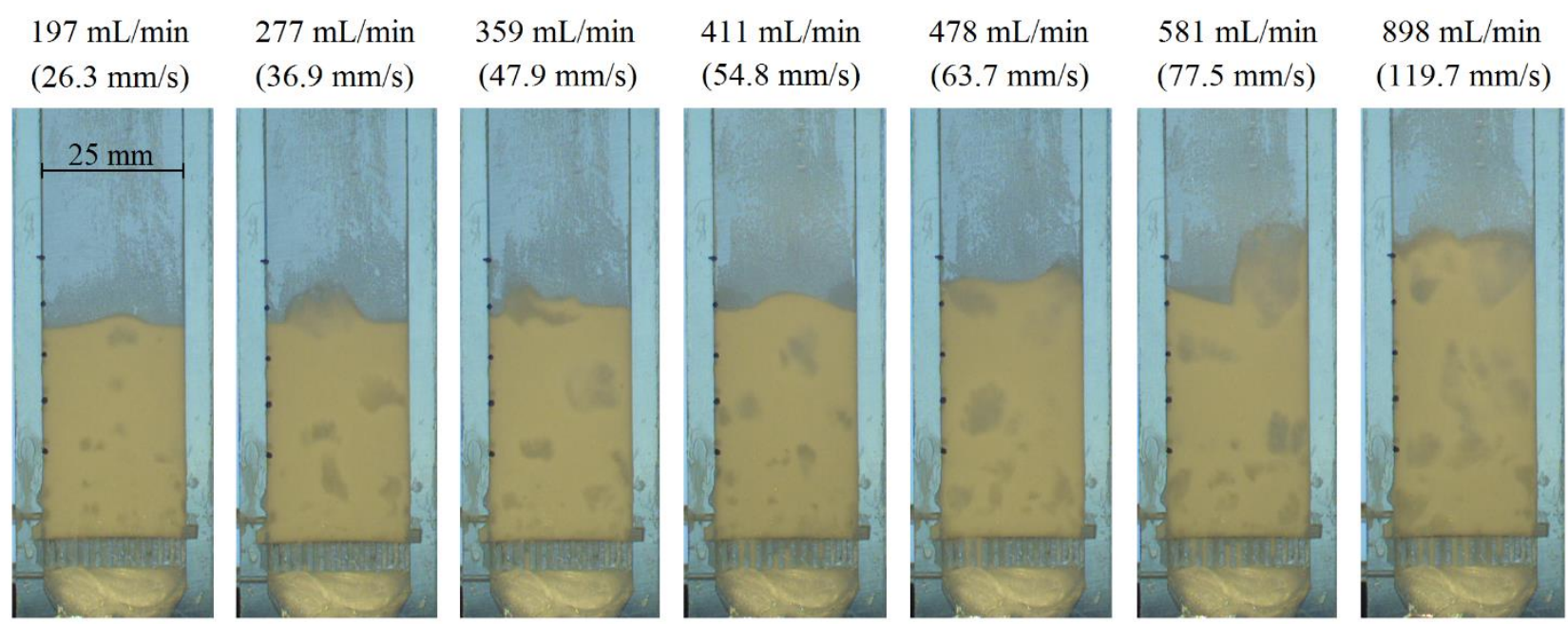

Figure 10. Snapshots of the bubbling fluidization of $93 \mu \mathrm{m}$ silica particles $\left(2.65 \mathrm{~g} / \mathrm{cm}^{3}, H / D_{t}=4\right)$ by air in a $3 D$ printed fluidized bed $(5 \times 25 \mathrm{~mm}$ cross-section $)$

\subsection{Small-Scale $\mathrm{CO}_{2}$ Adsorption Tests using Hydrotalcites}

Small-scale $\mathrm{CO}_{2}$ capture experiments will take place in two stages. In stage 1, adsorption will be investigated in semi-batch operation in an optimized fluidized bed geometry in a suitable flow regime identified from the hydrodynamics investigation. Then in stage 2 , both adsorption and regeneration of the sorbent will be studied simultaneously using a novel 3D printed circulating fluidized bed. These configurations are outlined schematically in Figure 11. 
(a)

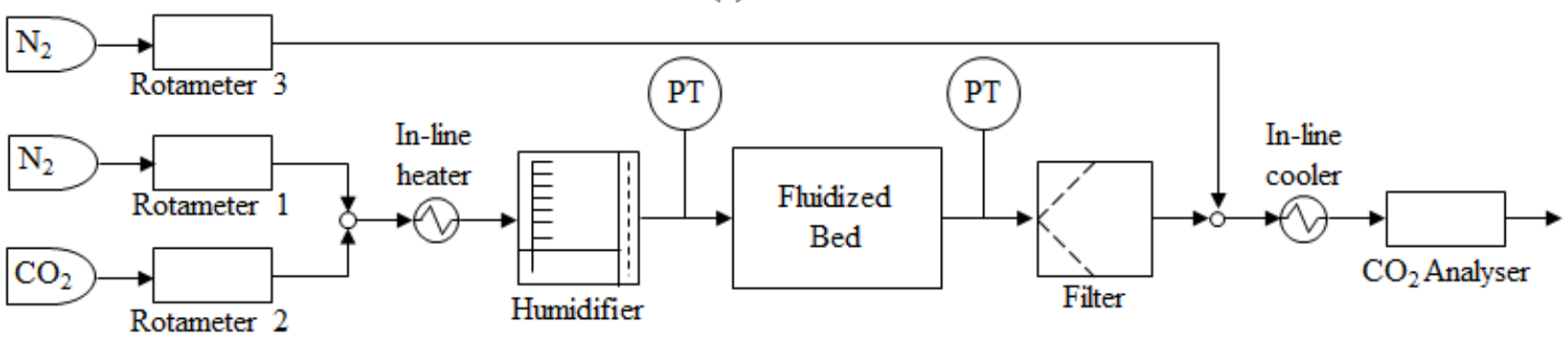

(b)

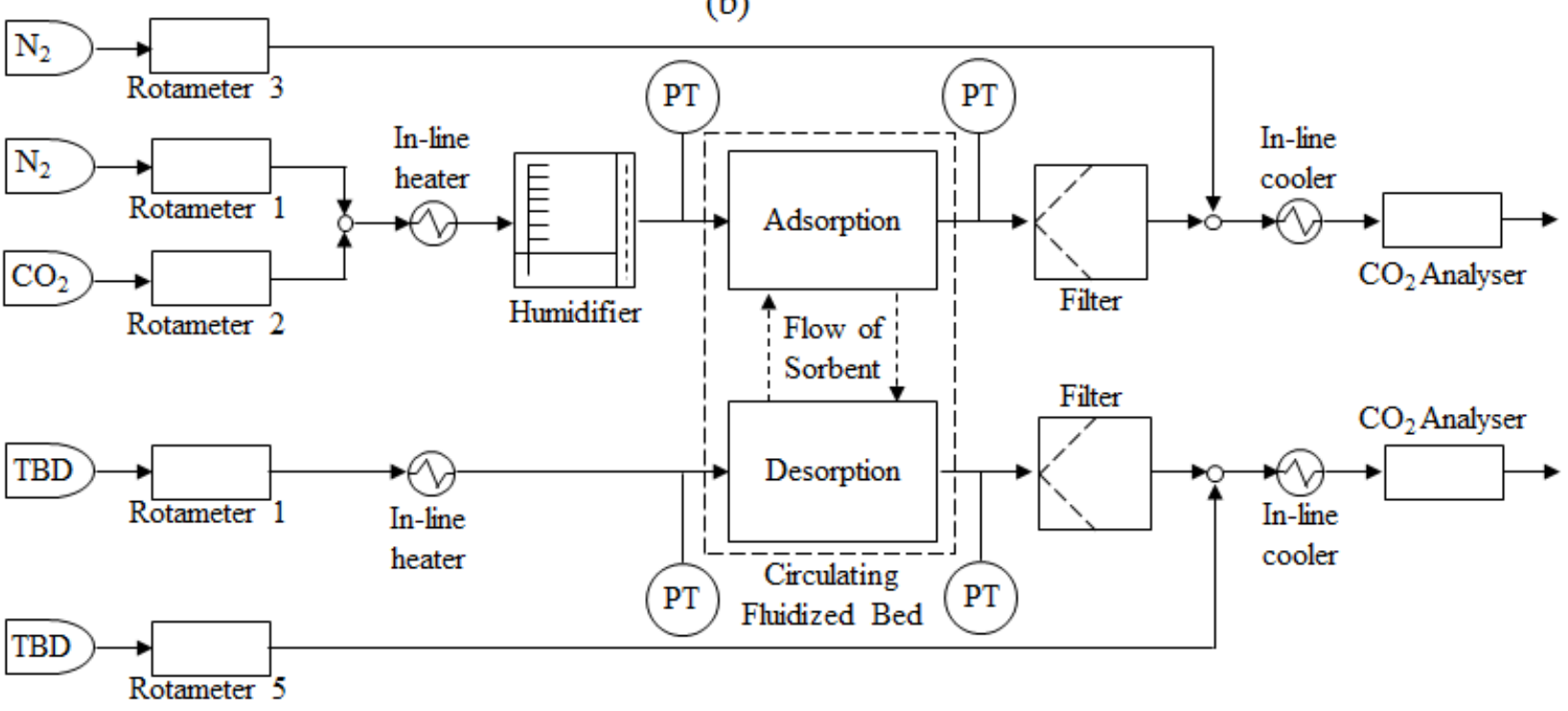

Figure 11 - Small scale $\mathrm{CO}_{2}$ capture experiment | (a) stage 1: adsorption only, (b) stage 2: adsorption and desorption

A flue gas analogue will be created by mixing $\mathrm{N}_{2}$ and $\mathrm{CO}_{2}$ in the desired stoichiometry, with the flow fates rates controlled using similar Omega flow meters to the hydrodynamics investigation. To ensure the adsorption experiments are conducted at conditions matching the industrial processes (Table 1) an in-line heater and humidifier will be used. The fluidized bed for these experiments will be fabricated from either a high-temperature polymer blend available for the Form 2 printer, or in stainless steel. As in the hydrodynamic experiments, a GE Druck LP1000 series pressure transducer (monitored with a PicoScope system) will be used to measure the pressure drop across the bed during the experiment. This measurement will be used to ensure the desired operating regime is maintained. An in-line cooler situated after the fluidized bed will be used to prepare exiting gas for the $\mathrm{CO}_{2}$ analyzer. The $\mathrm{CO}_{2}$ analyzer is a Vaisala CARBOCAP $\odot$ Carbon Dioxide Module (GMM111), which is suitable for $\mathrm{CO}_{2}$ concentrations of up to 5\%, $10 \%$ and 20\% depending on the selected measurement range. The minimum, optimal and maximum flow rates for this detector are 200 $\mathrm{mL} / \mathrm{min}, 800 \mathrm{~mL} / \mathrm{min}$ and $10,000 \mathrm{~mL} / \mathrm{min}$ respectively. A second nitrogen cylinder will also be used to adjust the total flow rate entering the $\mathrm{CO}_{2}$ analyzer to ensure the minimum flow rate is maintained.

For regeneration of the sorbent particles, a decision still has to be made as to which mode for desorption will be adopted. The options identified in Section 4 were fluidization in superheated steam or using a moving bed with internal heat exchanger. The option selected will have consequences for the design of the circulating fluidized bed system. However, the bulk of the sorbent regeneration rig will be the same, requiring an in-line heater capable of matching the target desorption temperature, pressure transducers, a sorbent filter, in-line cooler and second $\mathrm{CO}_{2}$ analyzer. If the superheated steam option is selected, a small-scale boiler will also be required. Alternatively, for the moving bed option, desorption will require just an $\mathrm{N}_{2}$ cylinder and additional rotameters. 


\section{Conclusions and Future Work}

The capture of $\mathrm{CO}_{2}$ from exhaust gas streams is driven by the need to reduce greenhouse gas emissions that cause global warming. There are several methods for removing $\mathrm{CO}_{2}$ from streams that originate from fossil fuel combustion processes, be they for power generation or to fuel industrial processes. This paper has examined the opportunities for capturing $\mathrm{CO}_{2}$ from processes in two industrial sectors, cement and iron and steel, which are responsible for a significant proportion of the up to $25 \%$ of the total European Union (EU) $\mathrm{CO}_{2}$ emissions that arise from industry.

Post-combustion capture commonly uses liquid absorption for removing the $\mathrm{CO}_{2}$ from gas streams, but an alternative method is to use gas-solid adsorption, where the $\mathrm{CO}_{2}$ is adsorbed inte onto a solid. The solid is normally in the form of particles of adsorbent, in a fixed bed. As with absorption, regeneration is required, and typically a single bed is employed to adsorb $\mathrm{CO}_{2}$ while regeneration and removal of the $\mathrm{CO}_{2}$ takes place in the second bed - carried out by pressure swing adsorption (PSA) or temperature swing adsorption (TSA). TSA has been shown to be more compatible with the industrial sources of waste heat examined here, and, in common with approaches to absorption carbon capture, it is believed that process intensification can aid process efficiency and reduce capital/installed cost and equipment sizes. This should help organisations making a case for retrofitting the equipment.

In this project, intensification of the adsorption process is to be achieved via fluidization of the adsorbent particles, in this case hydrotalcites. Preliminary examination of bubbling fluidization has been performed in polymer-based mini-scale fluidized beds fabricated using additive manufacturing to identify target flow regimes for $\mathrm{CO}_{2}$ capture screening experiments. The test facility has also been designed and in a future paper, experimental data will be presented.

Future Work: Initial tests will measure the adsorption capacities of the hydrotalcite materials synthesized at Heriot Watt in the mini-scale fluidized beds. Then, screening experiments will be performed in novel additive-manufactured mini-scale Swirling Fluidized Beds that more closely represent the larger throughput toroidal fluid bed that will form the basis of a practical industrial-scale carbon capture unit that can be retrofitted to industrial processes. Regeneration of the adsorbent will be tested at laboratory scale using either fluidization in superheated steam, or via a moving bed with an internal heat exchanger. These results will also help to guide the design of the industrial scale regeneration system using process waste heat.

\section{Acknowledgements}

This paper is an updated and extended version of a paper presented at the $15^{\text {th }}$ UK Heat Transfer Conference, 4-5 September 2017 at Brunel University London, UK.

The work is funded by the EPSRC under Grant No. EP/N024540/1 Novel Adsorbent Applied to Integrated Energy-efficient Industrial $\mathrm{CO}_{2}$ Capture. 


\section{References}

[1] Proceedings of the Committee on Climate Change. https://www.theccc.org.uk/tackling-climatechange/the-legal-landscape/european-union-legislation/ (Accessed 4 April 2017)

[2] Dickinson, J. et al. (2016). Oxidative degradation of amine absorbents in carbon capture systems - A dynamic modelling approach. Int. J. Greenhouse Gas Control 53, 391-400

[3] Reay, D.A. et al. (2013). Intensification of separation processes. Chapter 6 in: Process Intensification,

$2^{\text {nd }}$ Edition, Butterworth-Heinemann, Oxford, pp.205-249.

[4] Thakur, R.S. (2011). Process intensification in duplex pressure swing adsorption. Computers and Chemical Engineering 35 (5) 973-983

[5] EPSRC Grant No. EP/N024540/1 Novel Adsorbent Applied to Integrated Energy-efficient Industrial $\mathrm{CO}_{2}$ Capture.

[6] Kaewklum R, Kuprianov VI (2010) Experimental studies on a novel swirling fluidized-bed combustor using an annular spiral air distributor. Fuel 89. 43-52

[7] www.torftech.com Web site of Torftech - manufacturers of the Torbed toroidal fluidized bed system. (Accessed 20 April 2017)

[8] Gray ML, Champagne KJ, Fauth D, Baltrus JP, Pennline H (2008) Performance of immobilized tertiary amine solid sorbents for the capture of carbon dioxide. International Journal of Greenhouse Gas Control 2. 38

[9] Newey, D.C and Howard, J.R. (1983). The development of a novel fluidized bed gas-gas heat exchanger. Heat Recovery Systems 3 (1) 35-40

[10] Rackley, Stephen A., (2017). Carbon Capture and Storage, $2^{\text {nd }}$ Edition, Chapter 5 - Carbon Capture from Industrial Processes. Butterworth-Heinemann, Oxford, UK. http://dx.doi.org/10.1016/B978-0-12$\underline{812041-5.00005-2}$

[11] IPCC (2014). IPCC fifth assessment report: Mitigation of climate change. Intergovernmental Panel on Climate Change.

[12] Element Energy, Imperial College London, Ecofys, Stevenson P, Hyde, R (2014) The potential recovering and using surplus heat from industry: Final Report \& Appendices for DECC.

[13] LaMarche, C.Q. et al. (2016). Linking micro-scale predictions of capillary forces to macro-scale fluidization experiments in humid environments. AIChE Journal 62, 3585-3597

[14] Schneider M (2008) CO2 Capture and Storage: Options and Challenges for the Cement Industry. CSI Workshop. Beijing.

[15] Wiley D E, Ho M T, Bustamante A (2011) Assessment of opportunities for CO2 capture at iron and steel mills: An Australian perspective. Energy Procedia 4. 2654-2661.

[16] Griffin PW, Norman J B, Hammond G P (2014) Prospects for emissions reduction in the UK cement sector. Proc. Institute of Civil Engineers - Energy 167 (3) 152-161.

[17] Sharma U, Tyagi R, Jasra RV (2008) Synthesis and characterization of Mg-Al- $\mathrm{CO}_{3}$ layered double hydroxide for $\mathrm{CO}_{2}$ adsorption. Industrial \& Engineering Chemistry Research 47. 9588

[18] Dębek R, Motak M, Grzybek T, Galvez ME, Da Costa P (2017) A short review on the catalytic activity of hydrotalcite-derived materials for dry reforming of methane. Catalysts 7(1). 32

[19] Kim S, Jeon SG, Lee KB (2016) High-temperature $\mathrm{CO}_{2}$ sorption on hydrotalcite having a high $\mathrm{Mg} / \mathrm{Al}$ molar ratio. Appl. Mater. Interfaces 8. 5763-5767

[20] Gomes J, Santos S, Bordado J (2015) Choosing amine-based absorbents for $\mathrm{CO}_{2}$ capture. Environmental Technology 36(1). 19-25

[21] Yong Z \& Rodriques ARE (2002) Hydrotalcite-like compounds as adsorbents for carbon dioxide.

Energy Conversion and Management 43. 1865

[22] White MG, Iretskii AV, Weigel JS, Chiang RL, Brzozowski JR. International Patent No.

WO2004/000440 A1, 31 December 2003

[23] Oliveira ELG, Grande CA, Rodrigues AE (2008) $\mathrm{CO}_{2}$ sorption on hydrotalcite and alkali-modified (K and Cs) hydrotalcites at high temperatures. Sep. Purif. Technol. 62(1). 137-147

[24] Wang Q, Tay HH, Ng DJW, Chen L, Liu, Y, Chang J, Zhong Z, Luo J, Borgna A (2010) The effect of trivalent cations on the performance of $\mathrm{Mg}-\mathrm{M}-\mathrm{CO}_{3}$ layered double hydroxides for high-temperature $\mathrm{CO}_{2}$ capture. ChemSusChem 3(8). 965-973

[25] Wang Q, Wu Z, Tay HH, Chen L, Liu Y, Chang J, Zhong Z, Luo J, Borgna (2011). High temperature adsorption of $\mathrm{CO}_{2}$ on $\mathrm{Mg}$ - $\mathrm{Al}$ hydrotalcite: effect of the charge compensating anions and the synthesis $\mathrm{pH}$. 
Catal. Today 164(1). 198-203

[26] Hanif A, Dasgupta S, Dicekar S, Arya A, Garg MO, Nanoti A (2014) A study on high temperature $\mathrm{CO}_{2}$ capture by improved hydrotalcite sorbents. Chemical Engineering Journal 236. 91-99

[27] Tichit D, Rolland A, Prinetto F, Fetter G, Martinez-Ortiz MdJ, Valenzuela MA, Bosch P (2002)

Comparison of the structural and acid-based properties of Ga- and Al-containing layered double hydroxides

obtained by microwave irradiation and conventional ageing of synthesis gels. Journal of Materials Chemistry 12. 3832-3838

[28] Webley PA (2014) Adsorption technology for $\mathrm{CO}_{2}$ separation and capture: a perspective. Adsorption 20. 225-231

[29] Berger AH, Horowitz JA, Machalek T, Wang A, Bhown AS (2017) A novel rapid temperature swing adsorption post-combustion $\mathrm{CO}_{2}$ capture process using a sorbent polymer composite. Energy Procedia 114. 2193-2202

[30] MacDowell N, Florin N, Buchard A, Hallett J, Galindo A, Jakcson G, Adjiman CS, Williams CK, Shah N, Fennell P (2010) An overview of $\mathrm{CO}_{2}$ capture technologies. Energy Environ. Sci. 3. 1645-1669

[31] Lively RP, Chance RR, Kelley BT, Deckman HW, Drese JH, Jones CW, Koros WJ (2009) Hollow

Fiber Adsorbents for $\mathrm{CO}_{2}$ Removal from Flue Gas. Ind. Eng. Chem. Res. 48. 7314-7324

[32] Groszek M, Laughlin B (n.d.) Process Reactor Technologies [Online]. Torftech Ltd. White Paper available at: http://www.torftech.com/publications.html

[33] Lakshmanan VI, Dodson CE (1998) An innovative gas-solid Torbed reactor for the recycling industries. JOM 50(7). 29-31

[34] Sreenivasan B, Raghavan VR (2002) Hydrodynamics of a swirling fluidized bed. Chemical Engineering and Processing 41. 99-106

[35] Sheng TC, Sulaiman SA, Kumar V (2012) One-dimensional modeling of hydrodynamics in a swirling fluidized bed. International Journal of Mechanical \& Mechatronics Engineering 12(6). 13-22

[36] Kaewklum R, Kuprianov VI, Douglas PL (2009) Hydrodynamics of air-sand flow in a conical swirling fluidized bed: A comparative study between tangential and axial air entries. Energy Conversion and Management 50. 2999-3006

[37] Shu J, Lakshmanan VI, Dodson CE (2000) Hydrodynamic study of a toroidal fluidized bed reactor. Chemical Engineering and Processing 39. 4999-506

[38] Kuprianov VI, Kaewklum R, Charkritthakul (2011) Effects of operating conditions and fuel properties on emission performance and combustion efficiency of a swirling fluidized-bed combustor fired with a biomass fuel. Energy 36. 2038-2048

[39] Zhu S, Lee SW (2005) Co-combustion performance of poultry wastes and natural gas in the advanced swirling fluidized bed combustor (SFBC). Waste Management 25. 511-518

[40] McQueen MT (2003) Energy and high surface area siliceous ash from the combustion of rice hills, in $17^{\text {th }}$ International Fluidized Bed Combustion Conference, Jacksonville, Florida, US

[41] Sundaram P, Sudhakar P (2016) Experimental performance investigation of swirling flow enhancement on fluidized bed dryer. Journal of Engineering and Applied Sciences 11(21). 12529-12533

[42] Dodson CE, Lakshmanan VI, Laughlin RGW, Sridhar R, ORTECH Corporation (1999) Flash roasting of sulphide concentrates and leach residues using a Torbed reactor. Available at:

http://www.torftech.com/pdf/Flash\%20roasting\%20of\%20sulphide\%20concentrates\%20TMS\%201999.pdf

[43] Farrell W (1993) Case Study 216: Toroidal fluidized bed reactor for mineral processing [White Paper], Cape Industrial Products Ltd

[44] Lee CG, Cho YJ, Song PS, Kang Y, Kim JS, Choi MJ (2003) Effects of temperature distribution on the catalytic pyrolysis of polystyrene waste in a swirling fluidized-bed reactor. Catalysis Today 79-80. 453-464

[45] Dodson CE (1999) Torbed ${ }^{\circledR}$ reactor successfully treats PAH-contaminated soils. Technical Resources 17(1) $1.23-1.25$

[46] Pirklbauer J, Schöny G, Pröll T, Hermann H (2018) Impact of stage configurations, lean-rich heat exchange and regeneration agents on the energy demand of a multistage fluidized bed $\mathrm{TSA} \mathrm{CO}_{2}$ capture process. International Journal of Greenhouse Gas Control 72. 82-91

[47] Holm EL, Clausen JC (1988) Fluidized bed reactor and process for the operation of a fluidized bed reactor US Patent No. 4,788,919, Denmark

Fluidized bed reactor and process for the operation of a fluidized bed reactor. US Patent

[48] Roy S, Mohanty CR, Meikap BC (2009) Multistage fluidized bed reactor performance characterization 
for adsorption of carbon dioxide. Ind. Eng. Chem. Res. 48. 10718-10727

[49] UK Patent Specification 1500231 (1978). Improvements in or relating to heat exchangers. Inventors: Douglas Ernest Elliot and Michael John Virr, Patent filed 30 April 1974

[50] Lu P, Cao Y, Pan WP, Ma C (2011) Heat transfer characteristics in a horizontal swirling fluidized bed. Experimental Thermal and Fluid Science 35. 1127-1134

[51] Zabrodsky SS, Epanov YG, Galershtein DM, Saxena SC, Kolar AK (1981) Heat transfer in a largeparticle fluidized bed with immersed in-line and staggarered bundles of horizontal smooth tubes. Int. J. Heat Mass Transfer 24(4). 571-579

[52] Ramshaw C et al. (1987) Process Optimisation, p41 et seq., IChemE Symposium Series 100, Rugby, $\mathrm{UK}$

[53] Botterill JSM, Teoman Y, Yüregir KR (1984) Factors affecting heat transfer between gas-fluidized beds and immersed surfaces. Powder Technology 39. 177-189

[54] Hofer G, Schöny G, Fuchs J, Pröll T (2018) Investigating wall-to-bed heat transfer in view of a continuous temperature swing adsorption process. Fuel Processing Technology 169. 157-169

[55] Xavier AM, Davidson JF (1978) Fluidisation, Cambridge Univ. Press, Cambridge, UK

[56] Yusuf R, Halvorsen B, Melaaen MC (2012) An experimental and computational study of wall to bed heat transfer in a bubbling gas-solid fluidized bed. International Journal of Multiphase Flow 42. 9-23

[57] Patil DJ, Smit J, van Sint Annaland M, Kuipers JAM (2006) Wall-to-Bed Heat Transfer in Gas-Solid Bubbling Fluidized Beds. AIChE Journal 52(1) 58-74

[58] Zhang H, Degrève J, Baeyens J, Dewil R (2014) Wall-to-Bed Heat Transfer at Minimum Gas-Solid Fluidization. Journal of Powder Technology 2014, 163469

[58] Sulaiman SA, Miin CS, Naz MY, Raghavan VR (2016) Particle Image Velocimetry of a S9irling Fluidized Bed at Different Blade Angles. Chemical Engineering \& Technology 39(6). 1151-1160

[60] Kuprianov VI, Kaewklum R, Charkritthakul S (2011) Effects of operating conditions and fuel properties on emission performance and combustion efficiency of a swirling fluidized-bed combustor fired with a biomass fuel. Energy 36. 2038-2048

[61] Farrell W (1993) Case Study 216: Toroidal fluidized bed reactor for mineral processing. Cape Industrial Products Ltd. White Paper

[62] Lee C-G, Cho Y-J, Song P-S, Kang Y, Kim J-S, Choi M-J (2003) Effects of temperature distribution on the catalytic pyrolysis of polystyrene waste in a swirling fluidized-bed reactor. Catalysis Today 79-80. 453464

[63] Baskakov AP, Berg BV, Vitt OK, Filippovsky NF, Kirakosy VA, Goldobin JM, Maskaev VK (1973) Heat transfer to objects immersed in fluidized beds. Powder Technology 8. 273-282

[64] Flamant G, Fatah N, Flitris Y (1992) Wall-to-bed heat transfer in gas-solid fluidized beds: prediction of heat transfer regimes. Powder Technology 69. 223-230

[65] Groszek D. Introduction to the TORBED Technology and its role in Process Intensification. Presented at the $24^{\text {th }}$ Process Intensification Network Annual Meeting, $21^{\text {st }}$ June 2016, Newcastle University

[66] Daud WRW (2008) Fluidized Bed Dryers - Recent Advances. Advanced Powder Technology 19. 403418

[67] Coenen K, Gallucci F, Pio G, Cobden P, van Dijk E, Hensen E, van Sint Annaland M (2017) On the influence of steam on the $\mathrm{CO}_{2}$ chemisorption capacity of a hydrotalcite-based adsorbent for SEWGS applications. Chemical Engineering Journal 314. 554-569

[68] Wood J, Rong Y, Wang J (2014) Studies of hydrotalcite clays for $\mathrm{CO}_{2}$ adsorption. UKCCSRC Biannual Meeting, Cambridge, UK

[69] Romdhana H, Bonazzi C, Esteban-Decloux M (2015) Superheated Steam Drying: An Overview of Pilot and Industrial Dryers with a Focus on Energy Efficiency. Drying Technology 33, Issue 10

[70] Li J, Liang Q-C, Bennamoun L (2016) Superheated steam drying: Design aspects, energetic performances, and mathematical modelling. Renewable and Sustainable Energy Reviews 60. 1562-1583

[71] Bains P, Psarras P, Wilcox J (2017) $\mathrm{CO}_{2}$ capture from the industry sector. Progress in Energy and Combustion Science 63. 146-172

[72] IEA Greenhouse Gas R\&D Programme (IEA GHG) (2008) $\mathrm{CO}_{2}$ Capture in the Cement Industry, 2008/3

[73] SETIS (2013) Energy efficiency and $\mathrm{CO}_{2}$ reduction in the cement industry. European Commission

[74] Hassan SMN, Douglas PL, Croiset E (2007) Techno-economic study of $\mathrm{CO}_{2}$ capture from an existing cement plant using MEA scrubbing. International Journal of Green Energy 4. 197-220 
[75] Griffin PW, Norman JB, Hammond GP (2014) Prospects for emissions reduction in the UK cement sector. Proc. Institute of Civil Engineers - Energy 167(3). 152-161

[76] Hammond GP, Norman JB (2014) Heat recovery opportunities in UK industry. Applied Energy 116. 387-397

[77] Khurana S, Banerjee R, Gaitonde U (2002) Energy balance and cogeneration for a cement plant. Applied Thermal Engineering 22. 485-494

[78] Ho M T, Bustamante A, Wiley D E (2013) Comparison of CO2 capture economics for iron and steel mills. International Journal of Greenhouse Gas Control 19, 145-159.

[79] Carpenter A (2012) $\mathrm{CO}_{2}$ abatement in the iron and steel industry, IEA Clean Coal Centre, London, UK [80] IEA (2007) Tracking Industrial Energy Efficiency and $\mathrm{CO}_{2}$ Emissions. OECD/IEA: Paris, France [81] Bermúdez JM, Arenillas A, Luque R, Menéndez JA (2013) An overview of novel technologies to valorise coke oven gas surplus. Fuel Processing Technology 110. 150-159

[82] BCS Inc (2008) Waste heat recovery: technology and opportunities in U.S. industry. Available from: www.eere.energy.gov. Washington, DC, USA, U.S. Department of Energy, Office of Energy

[83] Wiley DE, Ho MT, Bustamante A (2011) Assessment of opportunities for $\mathrm{CO}_{2}$ capture at iron and steel mills: An Australian perspective. Energy Procedia 4. 2654-2661

[84] Sivakumar R, Saravanan R, Perumal AE, Iniyan S (2016) Fluidized bed drying of some agro products A review. Renewable and Sustainable Energy Reviews 61. 280-301 